NBER WORKING PAPER SERIES

\title{
CONTRACTING OVER THE DISCLOSURE OF SCIENTIFIC KNOWLEDGE: INTELLECTUAL PROPERTY AND ACADEMIC PUBLICATION
}

\author{
Joshua S. Gans \\ Fiona E. Murray \\ Scott Stern \\ Working Paper 19560 \\ http://www.nber.org/papers/w19560
}

\author{
NATIONAL BUREAU OF ECONOMIC RESEARCH \\ 1050 Massachusetts Avenue \\ Cambridge, MA 02138 \\ October 2013
}

Thanks to Dan Burk, Iain Cockburn, Julian Kolev, Mark Lemley, Michael Riordan, Chris Snyder, Glen Weyl, Heidi Williams, and participants at the 2008 Organisational Economics Workshop (Sydney), Workshop on Scholarly Communication (Michigan), Summer Workshop on Industrial Organisation (Auckland), 2009 International Industrial Organization Society Conference (Boston), 2009 Conference on the Patent Crisis (UC Irvine), 2010 NBER Summer Institute and seminars at Northwestern, Colorado, Stanford, Hong Kong, Melbourne, Queensland, the Australian National University, Wharton, Harvard, Toronto, Georgetown, Yahoo Research, Case Western, MIT and Boston. Thanks to Vivienne Groves for research assistance. JG acknowledges an ARC Discovery Grant for financial assistance. FM and SS acknowledge a National Science Foundation Science of Science Policy Grant. Responsibility for all errors lies with us. The latest version of this paper is available at research.joshuagans.com. The views expressed herein are those of the authors and do not necessarily reflect the views of the National Bureau of Economic Research.

At least one co-author has disclosed a financial relationship of potential relevance for this research. Further information is available online at http://www.nber.org/papers/w19560.ack

NBER working papers are circulated for discussion and comment purposes. They have not been peerreviewed or been subject to the review by the NBER Board of Directors that accompanies official NBER publications.

(C) 2013 by Joshua S. Gans, Fiona E. Murray, and Scott Stern. All rights reserved. Short sections of text, not to exceed two paragraphs, may be quoted without explicit permission provided that full credit, including $(\mathcal{C}$ notice, is given to the source. 
Contracting Over the Disclosure of Scientific Knowledge: Intellectual Property and Academic Publication

Joshua S. Gans, Fiona E. Murray, and Scott Stern

NBER Working Paper No. 19560

October 2013, Revised September 2014

JEL No. M55,O32,O34

\section{ABSTRACT}

This paper provides a theoretical investigation of the tension over knowledge disclosure between firms and their scientific employees. While empirical research suggests that scientists exhibit a "taste for science," such open disclosures can limit a firm's competitive advantage or ability to profitably commercialize their innovations. To explore how this tension is resolved we focus on the strategic interaction between researchers and firms bargaining over whether (and how) knowledge will be disclosed. We evaluate four disclosure strategies: secrecy, patenting, open science (scientific publication) and patent-paper pairs providing insights into the determinants of the disclosure strategy of a firm. We find that patents and publications can be complementary instruments facilitating the disclosure of knowledge-providing predictions as to when stronger IP protection regimes might drive openness by firms.

Joshua S. Gans

Rotman School of Management

University of Toronto

105 St. George Street

Toronto ON M5S 3E6

and NBER

joshua.gans@gmail.com

Fiona E. Murray

MIT Sloan School of Management

100 Main Street, E62-470

Cambridge, MA 02142

and NBER

fmurray@mit.edu
Scott Stern

MIT Sloan School of Management

100 Main Street, E62-476

Cambridge, MA 02142

and NBER

sstern@mit.edu 


\section{Introduction}

An enduring puzzle in the management of innovation is that many firms fund basic research and embrace practices from open science (such as publishing and conference participation) alongside their more traditional and applied development activities. Industry scientists even appear to have internal career paths tied to publishing success and career ladders that resemble those in academia with advancement solely through individual technical contributions (O’Mahony and Dahlander 2011). To explain these observations, scholars have hypothesized that open science practices serve as a "ticket of admission" to absorb scientific knowledge from academia, allowing firms to more rapidly reach the frontier and exploit first mover advantages (Rosenberg 1990; Cohen and Levinthal 1990). By implication, firms adopting open science practices are more productive. However, upon empirical examination, the adoption of open science by firms is found to be negatively correlated with the incomes of scientists at those firms (Stern, 2004). Moreover, patent quality may be negatively correlated with the magnitude of scientific impact of associated papers (Gittelman and Kogut 2002). This suggests that scientists themselves have a "taste for science" (Merton 1973; Dasgupta and David 1994) and that, in fact, firms face costs in engaging in scientific practices. This raises a critical question for scholars and for managers of innovation: What types of disclosure practices - particularly with regards to open and closed practices - should firms adopt? And, relatedly, as firms make these disclosure choices, what tradeoffs are being made with regards to firm-level competitiveness on one the hand and employee preferences one the other?

The importance of exploring the collection of disclosure practices that firms should adopt reframes the question of open science in a broader context. Specifically, while much of the current literature counterpoints open science with "closed" practices, such as intellectual property, there exist a wide variety of disclosure strategies that might be pursued. For example, trade secrets are widely used in industry but are rarely adopted in academia. Moreover, one of the distinguishing features of science as practiced by industry (compared to that practiced in academic settings) is the greater adoption of mechanisms to protect intellectual property. This includes patent protection, which, of course, involves some disclosures but can restrict use, as well as trade secrecy. Indeed, there is an increased incidence of patents being associated with publications of the same underlying research (Murray 2002; Azoulay, Ding and Stuart 2009) and 
this incidence is greater for industry than academia (Murray and Stern 2007).

The second of our key questions relates to the contractual relationship regarding disclosure between scientists and the firms who employ them. Studies of scientists' preferences for open science ignore the fact that firms have preferences and these preferences may be at odds with those scientists who desire open publication. Moreover, these studies ignore the fact that scientists may have more complex preferences over the bundle of disclosure approaches - not simply publication. For example, the recent Twitter employment contract suggests that scientists may have preferences over the use of their intellectual property: the firm provided employees with significant future control rights over the use of their patents, including commitments not to use the patents in "troll" situations. ${ }^{1}$ A similar commitment to "open science-like" practices can be observed with IBMs agreement to contribute intellectual property related to open source software. To complicate matters, scientists may have preferences with regards to combinations of disclosure practices. The backlash over the patenting (and publishing) of the Oncomouse discovery in the 1980s demonstrates that (academic) scientists resist attempts to exclude the use of research results through intellectual property protection and generally look with skepticism on practices that allow unfettered commercial exploitation of research (Bok 2003). Does this imply that industry scientists will be less interested in open science publication practices when they are combined with simultaneous patenting? Put more broadly, what is the negotiation that arises between industry scientists and the firms who employ them with regards to disclosure?

To date, there has been no thorough theoretical examination of the drivers of firm adoption of a full range of disclosure practices: open science publication alongside other commercial options, including secrecy and intellectual property. Thus, while the empirical studies show that scientists pay to be scientists (Stern 2004) - that is, accept lower salaries to engage in open disclosure through publication - in industry settings they cannot explain why some firms adopt those practices while others do not. If one were to take a pure "taste for science" view of the management of scientific workforces, we might expect that, in industries were intellectual property protection is weak (and, therefore, less consequential for firms), scientific practices would be more widely adopted as a means of economizing on labor costs. However, open science is most widely found in sectors such as the pharmaceutical industry where intellectual property protection is strong (Cockburn and Henderson 1998; Lim 1999). To

\footnotetext{
${ }^{1}$ https://blog.twitter.com/2012/introducing-innovators-patent-agreement (accessed 12 September 2014).
} 
account for these apparent puzzles, we propose a theoretical model that takes into account scientists' preferences on the one hand and firms' concerns over disclosure on the other. Thus, we can enable scholars as well as managers to sort out these competing effects and generate hypotheses for future empirical examination of firms' approaches to basic research.

One key advance inherent in our approach relates to the relationship between the type of research and disclosure. Some prior treatments have assumed that a simple mapping takes place from an organizational context - industry versus academia; to type of research - applied versus basic; to disclosure strategy - patents versus publications. However, more recent empirical evidence of universities' growing patent portfolios (Mowery et al. 2004; Jensen, Thursby and Thursby 2010; Sauerman and Stephan 2010) and the growing contribution to the scientific literature made by industrial scientists (Henderson and Cockburn 1996) indicate that no simple relationship exists between organizational arrangements and particular disclosure strategies. Ours is the first model to endogenize disclosure. By recognizing and formally modeling the ways in which one project has the potential to lead to a variety of disclosure outcomes, we can examine how these choices impact the relationship between scientists and commercial firms who employ them. ${ }^{2}$ Our focus on disclosure highlights the various channels through which the research outcomes of all projects may, in fact, be disclosed in an environment where it is possible for commercial firms to keep project outcomes secret or to patent and publish them.

Of equal import is the fact that our theoretical treatment explicitly links disclosure choices made by firms with the preferences of scientists. Our approach is in contrast to other studies that have modeled and empirically examined the relationship between openness and project selection (rather than disclosure), including, mostly notably, Aghion, Dewatripont and Stein (2008), who examined the governance of project direction and the degree of control that funders use to determine project choice (see also Lacetera 2010). Similarly, it has been shown that different incentives - implemented through the length of project funding periods - shape researchers' project selection (Azoulay et al. 2009). Initial team size (Wuchty, Jones and Uzzi, 2007) and structures of collaboration also serve as important organizational choices for knowledge production (Haeussler et al. 2011; Gans and Murray 2012). Jeon and Menicucci (2008) also examine the interplay between scientific and commercial rewards in determining the

\footnotetext{
${ }^{2}$ Mukherjee and Stern (2009) look at the broad choice between disclosure and secrecy in a dynamic setting but do not consider the interaction and feedbacks between this and a firm's other disclosure options such as patenting.
} 
choice of scientists between industry and academia in labor markets and the welfare consequences of these decisions. Likewise, Sauermann and co-authors have a line of research that uses survey data to explore scientists' interests in both academic and industry-oriented rewards (Sauermann and Cohen 2010; Sauermann and Roach 2014). What these approaches are missing, and what we provide, is a formal model that considers the interaction between scientists' preferences for alternative disclosure-based rewards and the consequences of these disclosure strategies for firm competitiveness.

The outline for the paper is as follows. In section 2, we provide a motivation for the main elements of our formal model - particularly, disclosure strategies and preferences. Section 3 then provides our formal model where we provide conditions - namely, the differential impacts of disclosure on competition and future licensing - that drive the relationship between publication rights and patenting. Section 4 then characterizes the equilibrium regimes and derives additional empirical insights along with the impact of alternative ownership of intellectual property. Section 5 considers how these results change in a simplified model of innovation racing between firms providing additional potential motivations for disclosure strategies that could change incentives for scientists in their innovative efforts. A final section concludes and offers future research directions.

\section{Disclosure of Scientific Knowledge: Model Elements}

The goal of our paper is to develop a theoretical model that examines how a firm's choices regarding the disclosure rights of its scientists interact with other elements of the firm's commercial and institutional environment; particularly, the firm's decision to pursue formal intellectual property protection. In so doing, we explicitly consider environments where knowledge has both a basic component (of value in academic publishing) as well as an applied component (of immediate use value); that is, to use recent classifications, that research is taking place within Pasteur's Quadrant (Stokes 1997), named after Pasteur's simultaneous advances in vaccination (a "product" of immediate value) and microbiology (scientific knowledge of value for future generations of innovators). It is in these environments where a firm's choices over the management of scientists have their greatest salience.

In this section, we consider the broad assumptions underpinning the formal model that follows in section 3 and the evidence supporting them. Specifically, we consider the disclosure 
strategies available to firms (with regard to both published and patented disclosures), the potentially conflicting preferences of scientists and firms over these strategies, and the process by which strategies are chosen or negotiated.

\section{Disclosure Strategies}

We consider research projects that generate both a product of immediate commercial value and also scientific knowledge that provides the foundation for future research in subsequent generations and for potential competitors in this generation. For projects of this type, the set of possible disclosure choices faced by firms is comprised of two elements: First, given the production of scientific knowledge of potential interest to future generations, the results from the research project may be published. This represents the collection of activities that comprise academic dissemination, including publication as well as the presentation of papers that augment the stock of publicly available knowledge (Dasgupta and David 1994). Second, given the production of immediately useful knowledge, it is possible to file a patent application disclosing what precisely is protected. If a decision is made not to patent, then this can lead to knowledge being kept secret. Taken together, this leads to four disclosure regimes that we term secrecy, open science, commercial science and patent-paper pairs. ${ }^{3}$ We examine each in turn.

Secrecy: It has been observed that, in the absence of incentives for disclosure provided by a range of institutions, knowledge production frequently leads to very limited disclosure and diffusion of knowledge (Mokyr 2004). Examples abound of inventions that operate under a regime of secrecy where for a significant (and perhaps indefinite) time, knowledge created is not disseminated. In seventeenth-century England, the Chamberlen family maintained the design of forceps and techniques for their use as a secret for three generations, thus ensuring their position as the leading (male) midwives of the era (Radcliffe, 1947). Not restricted to medical innovations nor to product designs, the secret formula for Coca-Cola has been retained by the firm as a trade secret rather than being disclosed in a patent. ${ }^{4}$ Similarly, Thomas' muffins actively maintains secrets to its recipes to protect the approximately $\$ 500$ million in yearly muffin sales (Neuman

\footnotetext{
${ }^{3}$ It is worth noting that this is the type of disclosure assumed to arise in the endogenous growth literature although not explicitly discussed as such. For example, Romer writes: "The crucial feature of the specification used here is that knowledge enters into production in two distinct ways. A new design enables the production of a new good that can be used to produce output. A new design also increases the total stock of knowledge and thereby increases the productivity of human capital in the research sector" (Romer 1990, p. S84).

${ }^{4}$ In recent years, several Coca-Cola employees have been charged with and found guilty of attempting to steal trade secrets from the company and sell them to Pepsi Co., resulting in prison sentences of up to seven years (http://money.cnn.com/2007/05/23/news/newsmakers/coke/index.htm).
} 
2010). Examples extend across a variety of industry sectors, from scientific instruments (Moser 2005) to Apple's ongoing attempts to control pre-launch information on products such as the iPhone. Indeed, a survey analysis by Levin et al. (1987) revealed the surprising importance of secrecy as a form of appropriability in many sectors, while Lerner (1994) observed that $43 \%$ of all IP litigations involve trade secrecy. Secrecy itself is grounded in a range of institutions, including formal trade secrecy law, non-compete agreements (Marx, Strumsky and Fleming 2009), non-disclosure contracts (Williams 2010), as well as non-disclosure clauses that are enabled by the inevitable disclosure doctrine within trade secrecy law (Lowry 1988).

Open Science: The institutional foundations of scientific publication in the academic literature are well established (Dasgupta and David 1994; David 2008). They provide a clear set of organizational arrangements through which scientific knowledge can be evaluated, certified and disclosed through peer-reviewed journals. Other less formal types of "publications" can include presentations at conferences, symposia and the writing of abstracts. More recently, the development of a range of online platforms for scientific knowledge has expanded the possibilities for scientists and firms engaging in what we broadly refer to as publication or "open science." Researchers are rewarded with reputation and kudos from their peers as well as opportunities for signaling their quality to future employers (Merton 1957; Dasgupta and David 1994; Stern 2004). ${ }^{5}$ A line of scholarly research has emphasized the expansion of publishing in scholarly journals and, most importantly for our purposes, the significant contributions to these journals made by scientists affiliated with for-profit firms (see Henderson and Cockburn 1996, and Gittelman and Kogut 2002 for early elaborations of the importance of this disclosure path).

Commercial Science: Governments, long recognizing the potential inefficiencies of secrecy, have developed national institutions allowing for property rights over novel inventive knowledge. The patent system lies at the heart of an institutional system that, among other functions, provides incentives to ensure that knowledge locked within firms or the minds of inventors might instead be disclosed (Machlup and Penrose 1950; Scotchmer and Green 1990). This incentive arises as patents can protect firms against imitative competition. First, a broader patent may make it more costly for competitors to enter with work-around products. Second, patents can block entry entirely; albeit in a probabilistic manner (Lemley and Shapiro 2005). As

\footnotetext{
${ }^{5}$ Also related are the norms of open source communities (Lerner and Tirole 2005). Mukherjee and Stern (2009) consider the tradeoff between scientific disclosure and secrecy in a dynamic model, although they do not explicitly model the negotiated outcomes between scientists and funders over disclosure strategy.
} 
a quid pro quo for such protection, patent holders must disclose knowledge to the level that enables a person "skilled in the art" to replicate that knowledge and potentially build upon it. Substantial empirical evidence illustrates the degree to which firms use patent disclosure strategies and under what conditions (Scotchmer 1996). More recently, this evidence has highlighted the expanding role of patent thickets and other more subtle uses of patent disclosure (Ziedonis 2004).

Patent-Paper Pairs: While the simple comparison between patenting and secrecy or publishing and secrecy provides some insight into the different possible disclosure strategies, this approach ignores a fourth alternative to disclosure through both patenting and publication; a strategy we refer to as patent-paper pairs (see Murray 2002). As noted above, for a project to result in disclosure through patent-paper pairs, the knowledge generated in a single research project must contribute to both scientific research and useful commercial (technical) applications. If it meets this test, then researchers can disclose their knowledge simultaneously in both institutions, garnering property rights through patents and making the research available to future generations of researchers. In projects of this type, the knowledge actually revealed in the patent and paper may be more or less congruent: At one end of the spectrum, projects may generate fundamental breakthroughs in respective scientific domains that are disclosed in papers, while the patents cover immediate applications of the knowledge. At the other end, it is possible to find examples where the knowledge disclosed through patents and papers is highly congruent; that is, it is the same knowledge being disclosed. ${ }^{6}$

While the notion of a patent-paper pair may appear to be a peculiar anomaly, in reality, pairs constitute the disclosure choices of private firms (as well as academics) across a range of disciplines. Consider the following examples drawn from the past fifty years of scientific research pursued by industrial scientists in chemistry, physics, biology and computer science in industry and academia:

\footnotetext{
${ }^{6}$ This feature of patent-paper pairs is illustrated with an example from genetics research focused on a gene known as BLNK (pronounced "blink") found on Chromosome 10. The BLNK gene encodes a B cell linker protein. In simple terms, proteins of this type sit on the surface of B cells and provide bridges between receptors and other proteins, regulating the biological functions of B cells. In 1999, scientists discovered the sequence and function of the BLNK gene and published their findings in a paper in Immunity, in which they said: "We describe here the identification of a novel B cell linker protein, termed BLNK, that interfaces the B cell receptor-associated Syk tyrosine kinase with PLCgamma, the Vav guanine nucleotide exchange factor, and the Grb2 and Nck adapter proteins" (Fu et al. 1998, p.93). The researchers also filed patent \#5994522 on BLNK proteins describing "the discovery of molecules which interact with either Grb2 or PLC- $\gamma$... play a role in the regulation of ... signaling pathways are desired. Accordingly, it is an object of the present invention to provide such molecules, termed 'BLNK' proteins, and to provide methods of using such molecules in screening assays." The paper provides no additional disclosure relative to the patent.
} 
- William Shockley described work at Bell Labs in his research notebook leading to the patent on the solid state transistor and he published breakthroughs on the theory of P-N junctions underlying the transistor (Shockley 1949).

- Knowledge of how to amplify DNA was developed at Cetus Corporation and was an important, published scientific discovery (leading to the 1993 Nobel Prize) and also a consequential patented and profitable invention (see Rabinow 1996).

- Researchers at Microsoft have used patent-paper pairs as a disclosure strategy for advances in computer science, including image processing. Patent 7,262,769 (filed 2004) discloses the inventors' "systems and methods for optimizing the geometric stretch of a parametrization scheme," and the same inventors are authors of a paper presented at the Eurographics Symposium on Geometry Processing (2004), "Signal-Specialized Parameterization for Piecewise Linear Reconstruction,"

Beyond specific examples, the coincidence of patent-paper pairs disclosing knowledge of related consequence has been extensively identified and studied by Ducor (2000), Murray (2002), Murray and Stern (2007) and Huang and Murray (2009). More recent empirical evidence from publications in scientific journals focused on biotechnology and nanotechnology illustrates that, for industry authors, the incidence of pairs is 54\% and 30\%, respectively (Fehder, Murray and Stern 2013).

In the management literature, patent-paper pairs have not been explored as a disclosure strategy. However, data on the extensive use of patenting and publication are suggestive of the fact that patent-paper pairs are the preferred disclosure strategy with considerable regularity. For example, among researchers identified as disclosing knowledge at leading R\&D firms (including DuPont, Merck, Intel and IBM), $10 \%$ to $25 \%$ are listed on both patents and publications (Lim 2004). The dual disclosure strategy of patenting and publishing is also widespread in biotechnology firms (Fabrizio and Di Minin 2008).

One additional observation is worth making about patent-paper pairs. The decision to pursue both patents and papers cannot be an afterthought but rather needs to be a clearly deliberated strategic choice. The reason for this is the timing requirements with respect to the ability to apply for and be granted a patent; that is, if publications precede patent application filing (by more than one year in the US), then the publication is considered to be prior art and the 
patent would be invalidated. ${ }^{7}$ This suggests that pairs are indeed part of a well-crafted disclosure strategy pursued by firms (as well as academics and their technology licensing officers) rather than a strange artifact of modern disclosure.

\section{Preferences}

In his work on the reasons behind private firm investments in basic research, Rosenberg (1990, p. 169) notes there is a basic tension between the preferences of scientists and those of firms. He writes:

Many scientists in private industry could honestly say that they are attempting to advance the frontiers of basic scientific knowledge, without any interest in possible applications. At the same time, the motivation of the research managers who decide to finance research in some basic field of science, may be strongly motivated by expectations of eventually useful findings.

While these divergent preferences can be broadly considered to incorporate differences over the types of projects being undertaken (see Aghion, Dewatripont and Stein 2008), they also, centrally, involve divergent views on the types of disclosures generated after project completion. Our model will capture this by assuming that scientists have a preference for disclosure through publication while firms seek to maximize profit. Here we review the literature justifying these assumptions.

Scientists: The institutional norms and career practices of academic scientists emphasize the importance of disclosure through the scholarly literature in the form of publication. To receive credit for the intellectual priority of their scientific discoveries, scientists publicize their findings as quickly as possible but retain no other rights over their ideas (Merton 1957). More subtly, these rewards - sometimes referred to as "kudos" - are related both to the significance of the published research relative to the existing literature and to the value, often judged ex post, that it adds to the pool of knowledge used by future generations of researchers. In simple terms, rewards are given for publication (a certification of significance) and citation (a certification of eventual relevance).

Publication-based rewards are obviously critical to the career concerns of universitybased scientists; however, empirical evidence suggests that scientists working in industry have similarly strong preferences for publication. As noted earlier, Stern (2004) provides strong

\footnotetext{
${ }^{7}$ Some papers consider a form of interaction between the patent system and publication via the strategy of defensive publication (Bar-Gill and Parchomovsky 2003), particularly in settings with patent races (Baker and Mezzetti 2005; Bar 2006; Johnson 2005). There is also a literature on the interaction between scientists' incentives and university technology transfer offices to disseminate patent applications (Macho-Stadler, Pérez-Castrillo and Veugelers 2007; Hellmann 2007).
} 
empirical evidence that scientists working in the private sector have strong preferences for disclosure through publishing (or presumably through patent-paper pairs, although this was not explicitly explored). ${ }^{8}$ Moreover, while career paths among scientists in industry are distinctive to those in academia, qualitative evidence suggests that publications and the rewards that come with it serve as important signals of credibility and are potentially important signals for promotion and job mobility (Stephan 2011). This suggests that even scientists employed in the private sector are motivated by concerns beyond purely monetary rewards. ${ }^{9}$ Their career incentives, when coupled with the socialization that arises during their research training, leads them to value their contributions to scientific knowledge and the recognition they garner in this activity (Merton 1957); that is, they have a "taste" for disclosure through publication (Roach and Sauermann 2010).

With regard to scientist attitudes towards formal intellectual property protection, there is no clear norm that arises from the institutions of science. Especially since the passing of the Bayh-Dole Act, universities have had strong incentives to patent scientific research for the explicit purpose of encouraging the dissemination of useful research results (Gans and Murray 2012). At the same time, there has been growing concern amongst scientists and those who study them that the pursuit of IP protection may hinder scientific processes (Heller and Eisenberg 1998; Nelson 2004; David 2008; Murray 2010). While building in an explicit preference against IP protection would be possible in the model below; instead, in the baseline model, we treat scientists as agnostic regarding IP protection itself but, in a dynamic extension, acknowledge they have concerns when that interferes with scientific norms; particularly, the reward to disclosure that arises through follow-on research and the citation of that research (Murray and Stern 2007).

Firms: For firms, we assume that they are interested in maximizing profits associated with the outcome of a research project. This means that firms carefully evaluate the consequences of disclosures, not only in granting publication rights to scientists, but also in whether they themselves pursue formal intellectual property protection. In so doing, we abstract away from longer-term arguments that firms may encourage disclosure as a "ticket of admission"

\footnotetext{
${ }_{9}^{8}$ See also Sauerrmann and Roach (2013) who provide insight into these mechanisms in a broader sample.

${ }^{9}$ It is well documented that scientists inside for-profit firms engage in high levels of publication activity. For example, in the period from 1985 to 1997, scientists at Intel produced 665 publications, while in the same period scientists at Merck produced over 10,000 publications (Lim 1999).
} 
into more academic processes that allow them to quickly move to knowledge frontiers (Rosenberg 1990; Cohen and Levinthal 1990). As noted earlier, we justify this abstraction based on the evidence that firms' wage practices do not incorporate such a value (Stern 1994) and that patent quality associated with published results may be low (Gittelman and Kogut 2002). In general, what is critical here is that, all other things being equal, firms would seek to limit the disclosure rights of scientists compared with what the scientists would themselves prefer.

Negotiation: In scientific labor markets, this tension between any given scientist and a firm is resolved through negotiation. That negotiation will take into account the disclosure strategy chosen by the firm and will be mediated by the wage the firm pays the scientist. Specifically, as the disclosure strategy moves towards one that is more favorable to the scientist's preferences (e.g., open science), the negotiated wage can be lowered (as in Stern 2004). However, critically, we assume that this cannot go too far. Scientists have limited wealth and so wages cannot be negative. Nonetheless, while in the formal model, this presents a technical challenge, and we demonstrate that our main results do not hinge on this particular constraint.

\section{Model Set-Up}

Our baseline model focuses on the nature of negotiations between a scientist and the firm. It should be noted that this model is structured to emphasize a scientist working for a for-profit firm (which could be a small entrepreneurial firm or a large organization) rather than for scientists working inside a university whose funding comes from a variety of sources and where norms of publication are strongly established. This allows us to derive a clearer insight into the nature of a firm's disclosure strategies and how it relates to environmental parameters.

\section{Modeling Disclosure Strategies}

We begin by describing the negotiations between a single scientist and single firm who form a research team for a project at a given period of time. We assume that they only undertake one such project. ${ }^{10}$ The scientist and firm engage in ex ante negotiations over the disclosure outcomes of the project. Disclosure, if it occurs, can be achieved through both patenting and publication. Specifically, the scientist and firm negotiate as to whether a project is patented or

\footnotetext{
${ }^{10}$ This is a stylistic rather than important assumption. One could equally view the scientist and firm negotiations to cover a set of projects that might comprise the scientist's career employment contract.
} 
not - that is, they agree on $i \in\{0,1\}$ where $i=1$ if they decide to patent and $i=0$ otherwise. Choosing to patent, with its protective benefits, involves a quid pro quo of certain disclosures, the minimum level of which is represented by a parameter, $d_{P A T}{ }^{11}$ Similarly, the firm and scientist must agree on how much information to disclose through publication. This is a negotiated choice, $d \in[0, D]$. A choice of $d=D$ represents full disclosure of the project's outcomes. When the firm and scientist choose $d=0$, we term this "no publication," whereas any agreed $d>0$ is considered a publication. ${ }^{12}$ Importantly, knowledge in a patent disclosure may overlap with knowledge disclosed through publication. The combinations of choices between patenting and publication give rise to the four possible broad disclosure regimes described earlier (see Figure 1).

Figure 1: Disclosure Strategies

\begin{tabular}{|c|c|c|c|}
\hline & \multicolumn{2}{|c|}{ Publication Rights } \\
\hline & & $d=0$ & $d>0$ \\
\hline \multirow{2}{*}{ 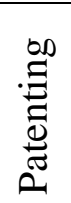 } & $i=1$ & $\begin{array}{l}\text { Commercial } \\
\text { Science }\end{array}$ & $\begin{array}{c}\text { Patent- } \\
\text { Paper Pairs }\end{array}$ \\
\hline & $i=0$ & Secrecy & $\begin{array}{c}\text { Open } \\
\text { Science }\end{array}$ \\
\hline
\end{tabular}

\section{Scientists and Firms}

The environment takes place in discrete time with periods denoted by $t \in\{0,1, \ldots, \infty\}$. All agents discount the future using a common discount factor, $\delta \in[0,1)$, per period. The population of agents in the model takes an overlapping generational structure in which each firm-scientist pair lives for two periods and one firm-scientist pair dies in each period while another firmscientist pair is born. In their first period, the "young" firm and scientist negotiate over various terms, research is conducted and immediate outcomes (profits, patents and publications) are realized. In their second period, the "old" firm and scientist may realize additional benefits or profit, as the case may be, while their next generation of "young" counterparts negotiate and

\footnotetext{
${ }^{11}$ Patenting, of course, involves other costs such as those associated with filing and enforcement that can impact on firms and scientists. We normalize these costs to zero but note that their inclusion would serve merely to reduce the returns to patenting and would not change any of the results obtained in this paper.

${ }^{12}$ It would be possible to imagine a situation where publication also required a minimum level of disclosure. Because, as will be argued below, scientists and firms disagree over the degree of publication disclosure but not over patent disclosures, we allow the level of publication disclosure to be a continuous variable with no positive lower bound. Imposing a lower constraint on the level of publication would have the effect of reducing the parameters for which publication might be observed.
} 
research.

Scientists are motivated by money (in the form of a wage, $w$ ) and scientific kudos that result from publication and citations by other scientists. ${ }^{13}$ Scientists are also presumed to be liquidity constrained and so cannot agree to any $w$ where $w<0 .{ }^{14}$ If they choose to participate in the project, the scientist's utility is represented by $U \equiv w+\left(b+I_{d_{t+1}>0} \delta B\right) d_{t}$ where $b+I_{d_{t+1}>0} \delta B$ is the marginal benefit of disclosure in terms of kudos, with $b$ being an immediate benefit (say, from publication) and $B$ that is only realized in the future if the scientist publishes $\left(d_{t}>0\right)$ and the future scientist publishes $\left(d_{t+1}>0\right)$ and cites the previous generation. ${ }^{15}$ To emphasize, a citation requires actual publication by that next generation. ${ }^{16}$ Non-participation in the project by the scientist gives each agent a payoff of zero. ${ }^{17}$ Note that this particular form of utility specification presumes that only disclosures through publication generate scientific kudos and patent disclosures do not matter for scientific prestige and rewards. ${ }^{18}$

Firms provide capital, $k_{t}$, for the scientist's research and pay the scientist's wages, $w$, (if any). Their profits, net of these costs, depend upon whether their disclosure, even in combination with patent protection (if any), gives their rivals or potential rivals an advantage. We assume that, if there is no competitive effect, the firm earns $\Pi$, but that a competitive effect reduces these profits by $\Delta(<\Pi)$. The probability that a firm faces a competitive effect is $F(i, d) \in(0,1)$, which is assumed to be, differentiable, non-decreasing and strictly concave in $d$ for all $(i, d)$. As will be discussed in detail below, the qualitative properties of $F($.$) with respect to i$ are ambiguous; because of disclosure requirements, $d_{P A T}$, a patent may help competitors rather than protect against them. Finally, if a patent is issued, the firm may earn a license fee, $\tau_{t+1}$, when it is old.

\footnotetext{
${ }^{13}$ This could also be paid in equity but would not change the results that follow.

${ }^{14}$ This is a natural assumption given it is the firm who provides capital for the project. If scientists had independent wealth, they could simply choose to provide that capital themselves; that is, exit and "spawn" a new firm (see Toole and Czarinka 2010).

${ }^{15} \mathrm{We}$ opt here for a reduced form of the impact of publication on scientist's utility. It would be possible to explore different mechanisms by which this impact occurred from pure intrinsic motivation to a more complex model of career concerns. While these models may yield insights into the behavior of scientists, what matters for the question under investigation here is that the scientist benefits more from publication than does the firm (who here is modeled to prefer less publication, ceteris paribus).

${ }^{16}$ Mukherjee and Stern (2009) posit a similar linkage between current publication and future kudos by making the assumption that scientist's utility increases with the level of follow-on research that is conducted. The difference here is that we derive more explicitly the implication in terms of primitives in the model so as to examine the impact of patent protection in this environment.

${ }^{17}$ It is possible to relax this assumption with the scientist receiving a positive reservation utility, but this does not alter the qualitative conclusions below.

${ }^{18}$ This assumption is made for notational simplicity. If the scientist's utility depended on patent disclosures, scientists would be more driven to disclose knowledge using patents. This would not, however, eliminate the conflict of interest between the scientist and the firm over disclosure. Hence, the main qualitative predictions would not change if we represented the utility of the scientist as depending upon publication as well as patent disclosures.
} 
Given this, a firm's expected payoff from agreeing to fund a scientist's research is $V_{t} \equiv \Pi-k_{i}-w_{t}-F\left(i_{t}, d_{t}\right) \Delta+\delta i_{t} \tau_{t+1}$. The firm and scientist, therefore, have conflicting preferences over the level of disclosures through publication.

\section{The Future Impact of Patents}

Finally, we make assumptions regarding the impact of patents on future generations. We assume that, if a patent is granted, the patent holder always negotiates with the next generation's research team. If these negotiations succeed, there is a transfer of knowledge between generations, meaning that no capital costs of research are incurred and a lump sum license fee, $\tau_{t}$, is paid. If these negotiations fail, then with probability $\gamma$, the new generation research team must choose a different research path. Thus, $\gamma$ is the probability that a patent blocks future research based on past knowledge. In this case, there is no knowledge transfer (future research teams incur the full capital costs, $\left.k_{t}=K\right)$. On the other hand, with probability $(1-\gamma)$, the new generation at time $t$ can, if there is a previous publication with disclosure level, $d_{t-1}$, exploit the knowledge from that publication in another way, despite failed negotiations. In this event, their expected capital costs becomes $k_{t}=k\left(d_{t-1}\right)$ where $k$ is a decreasing function with $k_{t}(D)=0$ and $k_{t}(0)=K{ }^{19}$ In this respect, $\gamma$ corresponds to a measure of the strength of future IP protection. ${ }^{20}$

We make no specific assumption as to whether a past publication is cited or not in the event of a breakdown in licensing negotiations. As already noted, there is some probability $(1-\gamma)$ that the young scientist-firm pair could proceed with a research path that allows them to exploit old pair's past publication. In that case, one could imagine that they avoid citing the past work as part of a strategy of working around previous patent rights (see Lampe 2012, for evidence). One interpretation of this is simply a desire to remove themselves as a litigation target by avoiding citation. Another is that the scientist-firm pair changes their research direction in order to avoid directly relying on the past technology while still taking advantage, should the opportunity arise, of scientific knowledge in the publication. Each of these might be regarded as consistent with Murray and Stern's (2007) findings of reduced citation following patent grants. However, the key results below do not hinge on this. Instead, it may be that citation occurs so long as some use

\footnotetext{
${ }^{19}$ These capital costs are not strictly equipment and infrastructure per se but the non-scientist effort cost in finding another path towards scientific progress.

${ }^{20}$ An alternative way of modeling the imperfection of future IP rights would be to assume that the uncertainty regarding patent enforceability was released prior to any negotiations. This alternative timing is more complex than the one we have chosen and does not appear to result in any additional significant qualitative conclusions.
} 
of the past publication is made. Nonetheless, when we come to consider whether scientists should own IP, whether a citation occurs or not following a breakdown is of importance.

A final model assumption is that, if no patent is granted, then the previous team is not involved in future negotiations. If there is no previous publication, there is no transfer of knowledge and the next generation team incurs the full capital costs, $K$. In contrast, if there is a previous publication, those capital costs are eliminated and the future scientist cites the past researcher, thus, generating kudos. ${ }^{21}$ In effect, this is an assumption that there is no contractual means of transferring knowledge in the absence of a patent. Under secrecy, this means that no transfer occurs, ${ }^{22}$ while under open science, such a transfer occurs and so there is no reason to contract for payment of that knowledge.

\section{Negotiations when there is no previous patent}

To build intuition, we begin by considering the case where the previous generation research team $(t-1)$ has chosen not to patent their innovation. In this case, in period $t$, the scientist and firm negotiate over a wage, $w_{t}$, and the disclosure strategy $\left(i_{t}, d_{t}\right)$. As noted above, we assume that the scientist has no financial capital and so the wage must be non-negative. We use the Nash bargaining solution to describe the outcomes of this negotiation. Specifically, under that solution, the following problem is solved:

$$
\max _{w_{t}, i_{t}, d_{t}}\left(w_{t}+\left(b+I_{d_{t+1}>0} \delta B\right) d_{t}\right)\left(\Pi-k\left(d_{t-1}\right)-w_{t}-F\left(i_{t}, d_{t}\right) \Delta\right)
$$

Note that we assume that the scientist and firm have equal bargaining power. ${ }^{23}$ To ensure that at least one of $w_{t}$ and $d_{t}$ that solve this problem are positive, it is assumed that:

$$
\min _{i_{t}} \Pi-K-F\left(i_{t}, 0\right) \Delta>0 \text {. }
$$

This implies that, at least in the best-case scenario for profits (i.e., when $d_{t}=0$ ), those profits are non-negative.

$$
\begin{gathered}
\text { Holding the disclosure strategy constant, the wage is given by } \\
\max \left[0, \frac{1}{2}\left(\Pi-k\left(d_{t-1}\right)-F\left(i_{t}, d_{t}\right) \Delta-\left(b+I_{d_{t+1}>0} \delta B\right) d_{t}\right)\right] \text {. In this case, notice that the kudos associated }
\end{gathered}
$$

\footnotetext{
${ }^{21}$ It would be possible to model the savings on capital cost as a function of the level of disclosure. This would not change the model's predictions, however, and so we opt for a simpler equivalence between unimpeded transfer through publication and a transfer alongside a patent.

${ }^{22}$ There are many possible rationales for this, but the most salient is Arrow's (1962) disclosure paradox whereby transfer of knowledge requires disclosure of it prior to contracting leaving the licensor open to expropriation.

${ }^{23}$ The model could easily be extended to parameterize the degree of bargaining power. Doing so, however, would not change our qualitative results.
} 
with publication lowers the wage received by the scientist. This is consistent with the findings of Stern (2004) that scientists' wages within firms are lower if they are allowed to freely publish their research results. Also, note that if disclosure through publication is sufficiently high, wages will fall to zero. The critical level of disclosure that results in zero wages is given by $\underline{d}$ such that:

$$
\Pi-k\left(d_{t-1}\right)-F\left(i, \underline{d}_{t}\right) \Delta-\left(b+I_{d_{t+1}>0} \delta B\right) \underline{d}_{t}=0 .
$$

Given our focus on settings where scientists are employed by a firm, we confine our attention to cases where wages will be positive. Thus, we make the following assumption:

(A1) $D<\underline{d}_{t}$.

This says that, even if all knowledge is disclosed, the left hand side of (3) will be positive, implying positive negotiated wages. In the appendix, we demonstrate that this assumption, in fact, does not alter any qualitative results derived, although the interpretation would change to environments beyond scientists' employment by firms and to where, say, scientists within universities receive commercial funding.

\section{Negotiations when there is a previous patent}

If the research team in $t-1$ did agree to $i_{t-1}=1$, then the owner of that patent (assumed to be the firm) will have a claim to outcomes from the next generation research team, specifically, over the transfer of knowledge. Thus, the two-agent negotiation modeled above turns into a three-agent negotiation.

To model the three-party bargaining game, should it emerge, we utilize a multi-lateral variant of the Nash bargaining solution. That solution is found by solving the following:

$$
\max _{\tau_{t}, w_{t}, i, d_{t}} \tau_{t}\left(w_{t}+b d_{t}+I_{d_{t+1}>0} \delta B d_{t}-u_{t}\right)\left(V_{t}-v_{t}\right)
$$

where the subscript, $t$, corresponds to the generation; $I$ is an indicator function taking a value of 1 if a publication occurs in $t+1$ and 0 otherwise; $u_{t}$ is the scientist's expected utility if no licensing agreement is reached; $V_{t}$ is the firm's expected payoff should a licensing agreement be reached with the old firm while $v_{t}$ is the firm's expected payoff in the absence of such an agreement. The outside options of the previous period's firm and scientist are the result of the bilateral negotiation between the scientist and firm as described when there is no past patent. Given (A1) that restricts attention to environments where wages are positive, we are able to focus on negotiation outcomes that maximize total surplus. 


\section{Disclosure Strategies}

We focus on symmetric dynamic equilibria in which each generation chooses the same disclosure strategy. ${ }^{24}$ Before formally characterizing the symmetric equilibria, it is useful to consider each disclosure strategy in turn.

Secrecy. Suppose that each generation chooses $i=0$ and $d=0$. Then research capital costs of $K$ are realized in every period and each generation of scientist-firm pairs earn their static outcomes; each has a payoff of $\frac{1}{2}(\Pi-K-F(0,0) \Delta)$ for the first period only. Note that there is no additional incentive for a single generation to deviate and publish other than the immediate benefits from publication because (as we will show formally below) the future generation has no additional incentive to publish as a result of this. In contrast, there is an incentive to patent since patenting allows the firm to obtain license fees in the future. In the absence of publication, by using the license and corresponding knowledge transfer, the future generation saves capital costs, $K$. In this case, they solve:

$$
\max _{\tau_{t}, w_{t}, d_{t}, i_{t}} \tau_{t}\left(w_{t}-u_{t}\right)\left(\Pi-F\left(i_{t}, 0\right) \Delta+i_{t} \delta \tau_{t+1}-w_{t}-\tau_{t}-v_{t}\right)
$$

Of course, in a symmetric equilibrium, $u_{t}=v_{t}=\frac{1}{2}(\Pi-K-F(0,0) \Delta)$. Consequently, assuming no other changes (that is, $d_{t}=i_{t}=0$ ), the license fee, $\tau_{t}$, equals $K / 3$. In this case, by choosing to patent, current expected surplus changes by $(F(0,0)-F(1,0)) \Delta+\delta \frac{1}{3} K$.

Commercial Science. Like secrecy, commercial science does not involve publication, and so if future scientists are not expected to publish, there is no additional incentive beyond the kudos from immediate publication for the current generation to publish. Here, however, a license fee is both earned and paid. Moreover, knowledge is transferred and so capital costs fall to 0 . Consequently, the scientist and firm each expect a payoff of $\frac{1}{2}\left(\Pi-\frac{1}{3} K-F(1,0) \Delta+\delta \frac{1}{3} K\right)$. Thus, if $\frac{F(0,0)}{F(1,0)} \geq 1$, the firm and scientist will have an ongoing incentive to continue patenting.

Open Science. Like the case of commercial science, open science does not result in research capital costs, $K$, being incurred by the next generation. In addition, the scientist receives kudos from publications and citations. Foregoing any agreed upon publication disclosure, $d_{t}$, would reduce total surplus by $(b+\delta B) d_{t}$.

Is there an incentive to deviate and patent? Deviating would allow the pair to earn

\footnotetext{
${ }^{24}$ We do not consider possible asymmetric equilibria whereby firms and scientists alternate their disclosure strategies from generation to generation, or choose their strategy contingent upon the disclosure strategy of the immediate past generation.
} 
$\left(F\left(0, d_{t}\right)-F\left(1, d_{t}\right)\right) \Delta$ in immediate profits as well as to earn a future license fee of $\tau=\frac{1}{3}\left(K-k\left(d_{t}\right)(1-\gamma)\right)$. Thus, compared with the transition from secrecy to commercial science, the transition from open science to patent-paper pairs involves a lower license fee.

Patent-Paper Pairs. In patent-paper pairs, the outcome of negotiations is the solution to:

$$
\max _{\tau_{t}, w_{t}, d_{t}, i_{t}} \tau_{t}\left(w_{t}+(b+\delta B) d_{t}-u_{t}\right)\left(\Pi-F\left(i_{t}, d_{t}\right) \Delta+i_{t} \delta \tau_{t+1}-w_{t}-\tau_{t}-v_{t}\right) .
$$

What is interesting is that the scientist's and the firm's outside options are influenced by the publication disclosures of the previous generation. The greater these are, the lower are the gains from trade from reaching a licensing agreement over the use of past IP. Nonetheless, these past decisions do not impact on the choice of publication. In this respect, joint surplus is maximized by publication if and only if:

$$
b+\delta B \geq \frac{\partial F\left(i_{t}, 0\right)}{\partial d_{t}} \Delta+i \delta \frac{1}{3} \frac{\partial k(0)}{\partial d}(1-\gamma) .
$$

Here, however, in contrast to the baseline model, the cost of publication is higher when there is a patent.

\section{Interaction between patenting and publication}

We are now in a position to examine the interaction between patenting and publication decisions arising from a negotiated disclosure strategy. The following proposition states the key result:

Proposition 1. Assume that (A1) holds. A necessary and sufficient condition for the negotiated level of disclosure through publication in any period $\left(d_{t}^{*}\right)$ to be non-decreasing in the choice of patenting $\left(i_{t}\right)$ is that $\left(\frac{\partial F(0, d)}{\partial d}-\frac{\partial F(1, d)}{\partial d}\right) \Delta+\delta \frac{1}{3} \frac{\partial k(d)}{\partial d}(1-\gamma) \geq 0$ for all $d$.

The proof of the proposition is in the appendix. ${ }^{25}$ To understand what drives it, note that $(i, d)$ are chosen to maximize the following joint surplus (a sufficient condition for which is (A1)):

$$
(b+\delta B) d+\Pi-k_{t}-F(i, d) \Delta+i \delta \frac{1}{3} k(d)(1-\gamma) .
$$

Observe that the marginal return to disclosure is:

$$
b+\delta B-\frac{\partial F(i, d)}{\partial d} \Delta+i \delta \frac{1}{3} \frac{\partial k(d)}{\partial d}(1-\gamma) .
$$

This is non-decreasing in patenting if the condition of the proposition holds. That condition is comprised of two components: the impact of disclosure on commercial profits from immediate

\footnotetext{
${ }^{25}$ The proof demonstrates that (A1) is not required for sufficiency part of Proposition 1. The impact of relaxing (A1) is discussed in the appendix where we note that a weaker condition guarantees the result from Proposition 1.
} 
competition and future licensing. First, if patenting is chosen, then increasing disclosure reduces the expected future license fees, that is, $\delta \frac{1}{3} \frac{\partial k(d)}{\partial d}(1-\gamma)<0$. Hence, so long as the research team cares about the future, $\delta>0$, then disclosure through publication, because it increases the ability of the next generation research team to acquire knowledge without formal licensing, involves additional costs. That said, if future intellectual property protection was secure (i.e., $\gamma=1$ ), then the magnitude of this effect falls to zero.

Second, a patent might change the marginal impact of disclosure through publication on the risk to commercial profits through competition. Specifically, if $\frac{\partial F(1, d)}{\partial d} \leq \frac{\partial F(0, d)}{\partial d}$, this implies that when a patent is taken out, the competitive consequences of greater disclosure are lower and, hence, the costs of permitting more disclosure are mitigated.

There are two broad reasons why it is likely that $\frac{\partial F(1, d)}{\partial d} \leq \frac{\partial F(0, d)}{\partial d}$. The first derives from the very nature of the patent system. Patent protection is designed to block imitative entry. That includes entry based on disclosures. For instance, suppose that $F()=.(1-i \rho) \Phi\left(i d_{P A T}, d\right)$. Here we interpret $\rho$ as the probability that a competitive response is blocked if the firm has a patent and $\Phi($.) is the competition-promoting qualities of disclosure. It is clear that, in the limit, as $\rho$ tends to 1 (blocking becomes perfect), there are no immediate adverse consequences to disclosure. More generally, the more effective a patent is in blocking imitative competition, the more likely it is that publication and greater disclosure through publication will be negotiated. Thus, the role of patents in reducing the likelihood of a competitive response has the natural consequence that they insulate the firm from the consequences of actions it may take that would otherwise promote that competition.

A second broad reason why $\frac{\partial F(1, d)}{\partial d} \leq \frac{\partial F(0, d)}{\partial d}$ comes from the possibility that disclosures in patenting and publication are not independent. In particular, those disclosures may overlap. To take an extreme, suppose that the knowledge disclosed in a patent and publication were identical. ${ }^{26}$ Then, if you were to choose to patent, there would be no additional cost, in terms of an increased likelihood of entry, to publish as well; and vice versa. In this extreme case, the twodimensional choice of the disclosure path turns into a single-dimensional choice of whether to disclose or not - with only secrecy or patent-paper pairs being observed.

Of course, in reality, patent and publication disclosures may not completely overlap.

\footnotetext{
${ }^{26}$ For instance, the BLNK gene research discussed above.
} 
Suppose that $F($.$) were increasing and concave in total disclosure, \Phi\left(i d_{P A T}, d\right)$; here written as $F(i, \Phi)$ to separate out the non-disclosure-related impacts of patenting. Under this specification, the marginal cost of publication disclosures would be $\frac{\partial F}{\partial \Phi} \frac{\partial \Phi}{\partial d} \Delta$. The impact of patenting can be seen by considering a "marginal" change in $i:\left(\left(\frac{\partial^{2} F}{\partial \Phi^{2}} \frac{\partial \Phi}{\partial i} d_{P A T}+\frac{\partial^{2} F}{\partial \Phi \partial i}\right) \frac{\partial \Phi}{\partial d}+\frac{\partial F}{\partial \Phi} \frac{\partial^{2} \Phi}{\partial d \partial i} d_{P A T}\right) \Delta$. The first term is negative by the concavity of $F($.$) while \frac{\partial^{2} F}{\partial \Phi \partial i} \leq 0$ for reasons described above. The second term will not reverse this so long as $\frac{\partial^{2} \Phi}{\partial d \partial i}$ is not too positive. In fact, it is likely to be negative, given the overlap in patent and publication disclosures. ${ }^{27}$

This demonstrates that in order for $\frac{\partial F(1, d)}{\partial d}>\frac{\partial F(0, d)}{\partial d}$, not only must the publication and patent disclosures be distinct, but also their combination must be promote more competition than their separate contributions. A circumstance such as this could conceptually arise when, for example, a patent discloses a tool or process while a publication discloses a product developed with the patented tool; for example, in chemistry when tools or processes could be covered by patents but when the product is the output of scientific interest. However, it is hard to envision a disclosure strategy of this type that would not also include a product patent (to foreclose imitative competition in the product market) or that would not also require disclosure of the process in the publication to enable other scientists. Thus, while this is theoretically possible, our examination of patents and associated publications suggests that it is unlikely.

In summary, the model here exposes that patenting and publication interact with one another through two different paths with qualitatively distinct impacts. First, publication reduces the likely returns from future licensing and, hence, reduces the expected returns from patenting. Second, the costs of publication in terms of assisting the firm's competitors are mitigated by the existing of a patent that could block a competitive response. Hence, patenting increases the expected returns from publication in the short run. The net effect of these two paths - the

\footnotetext{
${ }^{27}$ The effect of such overlap can be demonstrated in a reduced form model of learning. For instance, an entrant may need to learn a critical piece of information in order to imitate the firm. Let $i d_{P A T}$ and $d$ be the probabilities that the entrant learns that information from each disclosure path. Suppose that with probability, $\alpha$, patent and publication disclosures provide the same type of information. In this case, the probability that the entrant learns is $i d_{P A T}+d-i d_{P A T} d$. In contrast, with probability, $1-\alpha$, the knowledge that can be acquired through patent and publication disclosure is distinct. In this case, the probability that the entrant learns is $i d_{P A T}+d$. Thus, in expectation, at the time of the entry decision, the probability of learning through disclosure is $\Phi \equiv i d_{P A T}+d-\alpha i d_{P A T} d$. In this respect, $\alpha$ parameterizes the degree of congruence between patent and publication disclosures in terms of their usefulness in assisting entry. Note that: $\frac{\partial F}{\partial d}=\left(1-\alpha i d_{P A T}\right) \frac{\partial F}{\partial \Phi} \geq 0$ and that $\frac{\partial^{2} F}{\partial d \partial i}=-\alpha d_{P A T} \frac{\partial F}{\partial \Phi}+\left(1-\alpha i d_{P A T}\right)\left(d_{P A T}(1-\alpha d) \frac{\partial^{2} F}{\partial \Phi^{2}}+\frac{\partial^{2} F}{\partial \Phi \partial i}\right) \leq 0$ even when $\alpha=0$.
} 
immediate and the future - will determine the overall relationship between patenting and publication.

\section{Equilibrium Results}

Having set up the model and explored some basic relationships, we now turn to consider the equilibrium outcomes and provide broader predictions on the nature of disclosure strategies by research teams.

\section{Equilibrium Regimes}

As noted earlier, in choosing the level of publication, the scientist-firm pair must trade off the benefits the scientist receives from kudos against the potential for such disclosures to have adverse competitive consequences. In choosing whether to patent or not, the drivers are all on the firm's side of the negotiation. A patent impacts on competition in two ways. First, it makes life more difficult for competitors by increasing the probability that such competition is blocked or alternatively making competitive imitation more costly as a broader scope patent would require more investment in generating potential work-arounds. Second, the patent can actually help competitors through the disclosures made through the patent itself. For this reason, if $d_{P A T}$ is regarded as the minimal level of disclosure required to obtain a patent, we can expect that the firm will disclose no more than that minimum. ${ }^{28}$ Thus, we cannot say unambiguously whether $F($.$) is increasing or decreasing in i$ even if we can argue that $F(1, d)-F(0, d)$ is (weakly) increasing in $d$ (because the competitor assisting effects of disclosure are smaller if there is a patent). The following proposition summarizes the (symmetric) equilibrium regimes that emerge. $^{29}$

Proposition 2. The following represent symmetric equilibria in the dynamic game:

(i) Secrecy $(i=d=0)$ if $F(1,0)>F(0,0), \frac{b}{\Delta}<\frac{\partial F(0,0)}{\partial d}$;

(ii) Commercial Science $(i=1, d=0)$ if $F(1,0) \leq F(0,0), \frac{b}{\Delta}<\frac{\partial F(0,0)}{\partial d}$;

(iii)Open Science $\quad(i=0, \quad d>0) \quad$ if $\quad \frac{b+\delta B}{\Delta} \geq \max \left[\frac{F\left(0, d_{t}^{*}(0)\right)-F(1,0)}{d_{t}^{*}(0)}+\frac{\delta \frac{1}{3} K}{\Delta d_{t}^{*}(0)}, \frac{\partial F(0,0)}{\partial d_{t}}\right] \quad$ and $\frac{\delta \frac{1}{3}\left(K-k\left(d_{t}^{*}(1)\right)(1-\gamma)\right)}{\Delta}<F\left(1, d_{t}^{*}(1)\right)-F\left(0, d_{t}^{*}(0)\right) ;$

\footnotetext{
${ }^{28}$ As noted earlier, the literature has considered strategic reasons for firms involved in patent races to disclosure more than minimal amounts but this possibility would not change the qualitative results here.

${ }^{29}$ In stating the proposition, it is assumed that if the scientist-firm pair are indifferent between patenting and/or publication, they undertake those disclosures. Once again, we state the proposition for the case where $w$ is guaranteed to be positive. The appendix states conditions that emerge when $w$ may be constrained at zero.
} 


$$
\begin{aligned}
& \text { (iv) Patent-Paper } \quad \text { Pairs } \quad(i=1, \quad d>0) \quad \text { if } \quad \frac{b+\delta B}{\Delta}>\frac{\partial F(1,0)}{\partial d_{t}}-\frac{\partial k(0)}{\partial d_{t}} \frac{\delta \frac{1}{3}(1-\gamma)}{\Delta}, \\
& \frac{\delta \frac{1}{3}\left(K-k\left(d_{t}^{*}(1)\right)(1-\gamma)\right)}{\Delta} \geq F\left(1, d_{t}^{*}(1)\right)-F\left(0, d_{t}^{*}(0)\right) .
\end{aligned}
$$

An example of the equilibrium outcomes are depicted in Figure 2; where Figure 2a depicts a situation where the conditions of Proposition 1 hold (and patents and publications are complementary) whereas Figure $2 \mathrm{~b}$ is where those conditions are not satisfied. Interestingly, there can be multiple equilibria. The existence of multiple equilibria emerges because there is an intergenerational complementarity in publication decisions. Specifically, publication today is

only valuable if there is publication and citation tomorrow. Consequently, when $\frac{b}{\Delta}<\frac{\partial F(0,0)}{\partial d}$, there always exists a "non-communication" equilibrium involving $d_{t}=0$, since future expectation creates no additional incentives for publication today.

\section{The strength of intellectual property protection}

We are now in a position to analyze how the strength of intellectual property protection impacts on the type of disclosure regime negotiated between the firm and scientist. Recall that this was at the heart of the debate regarding the commercialization of science based on a concern that intellectual property protection will reduce the amount of disclosure of scientific knowledge - specifically through publication. Here, we explore this impact but, as will be apparent, the nature of intellectual property protection matters for the conclusions that the model draws. Importantly, note that intellectual property protection may be strengthened in terms of its protective short-term effect (through $F(1, d)$ ), its long-run effect on work-arounds (through $\gamma$ ) and its mandatory disclosures (through $d_{P A T}$ ). We examine each in turn.

Before doing so, it is useful to distinguish between two types of effects arising from a change in the strength of intellectual property protection. First, under patent-paper pairs where both disclosure paths are utilized, a strengthening of intellectual property protection may change incentives to disclose through publication on the intensive margin. Second, a change in intellectual property protection may change the disclosure regime chosen by the firm and, hence, impact on the extensive margin. Specifically, it is straightforward to see that any strengthening in patent protection increases the returns to having a patent. Thus, it may facilitate a change from secrecy or open science into another regime. In what follows, we will distinguish between these two impacts.

First, in the short run, a strengthening of intellectual property protection decreases $F(1, d)$ 
for all $d$. That is, a stronger patent reduces the probability that the firm will face a competitive response and lose $\Delta$. Recall that we argued above that there was a strong case that $\frac{\partial F(1, d)}{\partial d} \leq \frac{\partial F(0, d)}{\partial d}$; that is, the negative impact of disclosures on the probability of entry is itself increasing in whether the firm has a patent or not. Similarly, we can argue that, as more publication disclosures are made (i.e., $d$ increases), $F(0, d)-F(1, d)$ will increase. That is, if your intention is to publish more, then the marginal value of a patent in protecting against a competitive response is higher even as the probability of that competitive response rises. Note that, formally, $\frac{\partial F(1, d)}{\partial d} \leq \frac{\partial F(0, d)}{\partial d} \Rightarrow \frac{\partial(F(0, d)-F(1, d))}{\partial d} \geq 0$, so these statements are equivalent. It is straightforward to see that, in this situation, as strong intellectual property protection increases $F(1, d)$ without impacting on $F(0, d)$, holding $d_{P A T}$ and $\gamma$ constant, then, on the intensive margin, the negotiated level of disclosure through publication will also increase. If the condition of Proposition 1 holds, then the extensive margin impact will have the same sign as the intensive margin one. However, if not, there may be conflicting effects and the overall effect is ambiguous. For instance, an increase in the short-run strength of patents may cause the disclosure regime to move from open science to patent-paper pairs. If publications and patents are not complements overall, we cannot say whether or not publications will rise as a consequence of this change. However, if the longrun impact of publication disclosures on license fees are not important (say as $\gamma \rightarrow 0$ ), then patents and publications will be complements and stronger short-run patent protection will be associated with a rise in publication rights.

A similar set of issues apply to an increase in patent disclosure requirements $\left(d_{P A T}\right)$, which has an ambiguous impact on the degree of disclosure. While it is the case that increasing the disclosure requirements through patenting does reduce the marginal cost of disclosing through publication (and hence, increases the likelihood that a commercial science regime becomes a patent-paper pair regime), it does so by increasing the firm's cost of patenting. ${ }^{30}$ In the process, a higher $d_{P A T}$ results in a weakening of the incentives to take out intellectual property protection leading to, in particular, a greater likelihood that secrecy will be chosen over other regimes. Conversely, reducing $d_{P A T}$ makes patenting more likely to be chosen (and so leads to greater levels of disclosure through that pathway), and also, within patent-paper pairs, allows the

\footnotetext{
${ }^{30}$ Strictly speaking, what we are concerned with here are disclosure requirements that might assist entry. This could be a simple increase in $d_{P A T}$ or it may be a requirement that patent disclosures should be more like disclosures through publication. Either interpretation gives rise to the same qualitative effects discussed here.
} 
scientist to negotiate greater levels of disclosure through publication. Thus, this change in IP protection alters the type of disclosure that we observe. Nonetheless, we cannot say conclusively whether a change in $d_{P A T}$ would result in an increase or decrease in disclosure.

Finally, an increase in $\gamma$ raises the incentives to take out a patent and, to a degree, this reduces the domains of open science and secrecy on the extensive margin. At the same time, however, as can be seen from (7), this decreases the costs associated with publication. Those costs arise because patents cannot perfectly protect future licensing revenues from the adverse consequences of publication disclosures. Consequently, the domain of patent-paper pairs will also be reduced (both in the domains of open and commercial science). The overall dynamic effect, therefore, of a weakening of intellectual property protection is ambiguous. Indeed, in the limit as $\gamma$ approaches 1 (and patents become perfectly strong), the future substitutability effect between patents and papers disappears. This suggests that the full-equilibrium interpretation of results, that patent protection is associated with a reduction in citations or in a substitution away from building on patented knowledge, is subtle. While moves to limit future licensing (such as preventing reach-through rights or allowing for a research exemption) might appear to address these issues directly, this also changes the disclosure incentives of researchers.

In summary, this analysis demonstrates that it is the role of future licensing that determines whether clear predictions regarding the impact of stronger intellectual property protection can be made. Put simply, in the absence of concerns about the impact of disclosure on future licensing - either because such licensing is not important $\left(\frac{\partial k}{\partial d} \approx 0\right)$ or future intellectual property protection is itself strong $(\gamma \approx 1)$ - then taking out a patent is and publications are complements and, hence, stronger patent protection, by raising the effectiveness of patents (the intensive margin) and/or increasing the incentives to take out a patent (the extensive margin), reinforce one another to cause the firm and scientist to negotiate more extensive publication rights. By contrast, while it is always the case that raising the effectiveness of patents causes more publication rights through the intensive margin, when concerns about future licensing are strong, there is a mitigating effect on the extensive margin, and so an unambiguous prediction is not possible from the theory.

\section{Discussion of Evidence}

As noted in section 2, there has been an extensive literature documenting the co-existence 
of patents and publication, and our model here provides a theory that demonstrates that even when firms and scientists face conflicts over disclosure, co-existence is possible. Moreover, under some conditions (as in Proposition 1), they are complements and the existence of one reinforces the presence of the other. There is, however, a smaller literature that examines the association between patents and publication that would inform as to whether there is, in fact, complementarity or substitutability and allow us to make some inferences regarding the magnitudes of the conditions examined in Proposition 1.

There are, however, papers that point to a negative association between patents and publication. For instance, Murray and Stern (2007) find that patented research is less likely to be cited than research not subject to patents. However, their paper does not identify a mechanism that would cause a scientist to avoid such citation. The mechanism in the present paper that would account for this would be a concern by scientists that they would be subject to license payments if they did not find a way to work around (or without) the patented research.

More closely related to the context in the present paper is Bhaskarabhatla and Hedge's (2014) study of IBM's decision to encourage patenting in 1989 after long-standing alternative policies. While they examine many potential consequences of that decision, they found that there was an associated drop in publication rates (including in scientific journals) by IBM inventors in the 1990s. They also found that there was an associated fall in citations by others to IBM research. While Bhaskarabhatla and Hedge are careful not to ascribe any causal inference from these findings, they do document that IBM's new patent policy was associated with a greater reliance on license fees; something that in our model here is associated with substitutability between patents and publications.

To obtain a causal relationship, empirical researchers would need to find a situation whereby an exogenous shock intensified the propensity to patent or publish in an industry or firm. For instance, consider the substantial increase in the patent disclosure and inventive-step requirements of gene patents in 2001, along with calling into question the strength of patents by the 2000 joint Clinton-Blair announcement on the use of genetic information. ${ }^{31}$ Following this, publications in the area of molecular genetics from companies such as Human Genome Sciences declined as a result of the shift to greater levels of secrecy and the lack of complementary patent

\footnotetext{
${ }^{31}$ White House Press Release June 26, 2000: PRESIDENT CLINTON ANNOUNCES THE COMPLETION OF THE FIRST SURVEY OF THE ENTIRE HUMAN GENOME: Hails Public and Private Efforts Leading to This Historic Achievement.
} 
protection for genetic information. ${ }^{32}$ This suggests that it may be possible to find industryspecific causal inferences that allow us to better understand the relationship between patents and publication.

\section{Ownership of IP rights}

In the analysis thus far, firms are assumed to be the owners of patents and, hence, the only party that participates in future negotiations over license fees. This means that firms have no interest in the disclosure decisions of future generations and, indeed, given their hold-up power, only care about future capital costs. But what if scientists, instead of firms, owned IP rights? The effect on the immediate competitive environment might be unchanged, but if the scientists had previously published then, in licensing negotiations, they would care about the publication outcomes of the next generation of scientists. More importantly, scientists might fear that, in the event of a breakdown, they would not be cited and they would not receive their rightful kudos. The implication of this is that, in patent-paper pairs, where this is relevant, the scientist would discount the license fee to take into account the ability of the next generation to hold up the value of their kudos.

This can be seen by examining the Nash bargaining objective under this new assumption:

$$
\max _{\tau_{t}, w_{t}, d_{t}, i_{t}}\left(I_{d_{t}>0} B d_{t-1}+\tau_{t}\right)\left(w_{t}+(b+\delta B) d_{t}-u_{t}\right)\left(\Pi-F\left(i_{t}, d_{t}\right) \Delta+i_{t} \delta \tau_{t+1}-w_{t}-\tau_{t}-v_{t}\right) .
$$

The presence of the old scientist causes them to negotiate a lower license fee by an amount positively related to the level of past publication $\left(d_{t-1}\right)$. This is anticipated in their own negotiations when they are young with their equivalent generation firm. The reduced license fee will increase the costs of publication disclosure for that team. Consequently, the domains for open science and patent-paper pairs would shrink relative to the case where only the firm owned patent rights. Intuitively, by bringing future kudos to the bargaining table as a valuable item, giving scientists ownership rights would shift some of the value of kudos to future generations. As licensing agreements are accepted, this shift in value is a mere transfer. Nonetheless,

\footnotetext{
${ }^{32}$ In the period from the founding of Human Genome Sciences in 1993 until the joint presidential announcement in 1999 and the discussions in the USPTO regarding the strengthening of the enabling requirements for gene patents, HGS published over 200 publications and 280 patents, with 52 research articles published in 1999 and the filings of 77 patent applications (that were subsequently granted). From 2000 onwards, publications have been in decline with fewer than 40 publications each year from 2001 until 2004, dropping off again in the period after 2006. In contrast, patent filings increased, with over 100 patents filed each year in the period 2001-2004 and over 70 each year in the years following. We interpret the stable and even growing trend in patents with the decline in publications to be consistent with the view that as patents are potentially (probabilistically) weakened, their complementarity with publishing declines and thus the disclosure in publications is lowered. [Data taken from ISI Web of Science and USPTO]
} 
compared to situations when firms own IP rights, the lower appropriation of kudos biases against agreements that involve publication.

\section{Races for Priority and Publication Rights}

We now turn to consider an alternative reason why private firms may choose to commit to some degree of disclosure through publication: that is, scientific disclosure can reduce the costs associated with generating more rapid innovation. We do this in an environment where, to research more intensively, scientists face an opportunity cost which could be effort or time devoted to unfettered research. Moreover, we assume that a scientist's choice of research intensity is non-contractible.

As this is a more complex environment, we make some assumptions that simplify the environment of the baseline model. First, we remove the dynamic reach of publications and patents by considering our analysis from the perspective of a single generation of research teams. Thus, $B=\gamma=0$. Second, we assume that $k_{t}$ is invariant over time and is simply equal to $k$ and sufficiently low that firms want to undertake the project. Finally, it is assumed that $d_{P A T}=0$, so that patenting is always optimal.

\section{Single Research Team}

We consider a simple model of research intensity whereby research can be completed either today (period 1) or tomorrow (period 2). ${ }^{33}$ As before, the common discount factor is $\delta$ and there is no explicit uncertainty.

To complete research today rather than tomorrow, the scientist incurs a cost of $c$. We assume that, from the perspective of total surplus, researching intensively today is always desirable. That is,

$$
(1-\delta) \max _{d}\{b d+\Pi-F(1, d) \Delta\}>c .
$$

In this situation, if it was surplus maximizing for there to be no publication (i.e., $d=0$ ), then the firm would have to pay the scientist a wage to participate as well as a payment for delivery of research today rather than tomorrow. As we assume research is non-contractible, that latter mechanism is not available. Consequently, the only instrument available to the firm to accelerate

\footnotetext{
${ }^{33}$ This mirrors the infinite time horizon models of Gilbert and Newbery (1982) and Katz and Shapiro (1987), and also contains elements of their stochastic analogues (Reinganum 1989). It is also the case that a "period" here involves a shorter actual period of time than was the case for a "period" in our baseline model in section 3.
} 
research by the scientist is the level of disclosure through publication that is permitted. Thus, at the outset, the scientist and firm will negotiate over a disclosure level with the decision of when to complete research being left to the scientist.

In this situation, if it wants to encourage timely research, the firm must permit a disclosure level of at least $d \geq \hat{d} \equiv \frac{c}{(1-\delta) b}$. We assume that $\hat{d}<D$ to focus on the interesting case where such disclosures exist. Alternatively, the firm can simply accept delay. Thus, the firm will choose to motivate timely research if:

$$
b \hat{d}+\Pi-F(1, \hat{d}) \Delta \geq c+\delta \max _{d \leq D}\{b d+\Pi-F(1, d) \Delta\} .
$$

In our baseline analysis, without research "effort" being a factor, publication (to some degree) would be permitted if:

$$
b \geq \frac{\partial F(1,0)}{\partial d} \Delta
$$

Suppose this condition does not hold. Then, $\arg \max _{d \leq D}\{b d+\Pi-F(1, d) \Delta\}=0$, and the firm would choose a positive level of publication (i.e, $d \geq \hat{d}$ ) if:

$$
\frac{\delta c}{1-\delta}+(1-\delta) \Pi \geq F\left(1, \frac{c}{1-\delta}\right) \Delta-\delta F(1,0) \Delta,
$$

which can hold. Thus, there are circumstances where publication is strictly surplus-reducing, but the firm and scientist will both agree to publication in order to motivate timely research.

\section{Competing Research Teams}

Now suppose that there were two scientists and two firms that were paired in a competition for priority, both in publication (if they agree to disclose) and in obtaining a patent. If one firm completes research before the other firm, it obtains the patent. If both firms complete research in the same period, each has an equal chance of being granted the patent. Also, suppose that the firms have no opportunity for further profits should they lose the patent race.

We continue to suppose that $b<\frac{\partial F(1,0)}{\partial d} \Delta$, so that publication is not optimal in the absence of providing an incentive to motivate scientists. Consider first a situation where neither of the firms has agreed to publish and so both research teams will delay completion. In this case, in order to motivate its scientists to research more intensively, a firm has to choose a disclosure level of at least $\hat{d}$; the same level as in a single research team scenario. This is because, when the other research team is not publishing, there is no race for scientific priority through 
publication. Thus, scientific competition does not operate. Nonetheless, commercial competition does operate and, in the event the firm delays research, its expected profits fall by one-half. So the condition whereby it is desirable for the firm to give the scientist publication rights is:

$$
\frac{\delta c}{1-\delta}+\left(1-\frac{1}{2} \delta\right) \Pi \geq F\left(1, \frac{c}{1-\delta}\right) \Delta-\frac{1}{2} \delta F(1,0) \Delta .
$$

As $\Pi>\Delta$, it is readily apparent that this inequality is weaker then the condition in (14). Thus, participating in a race for priority increases the range of parameters whereby, in equilibrium, at least one firm offers its scientist publication rights.

When will there be an equilibrium that allows both firms to allow publication? For this to occur, the level of disclosure chosen by a team would have to satisfy $d \geq \hat{\hat{d}} \equiv 2 \frac{c}{b}$. Note that $\hat{\hat{d}}<\hat{d} \Rightarrow 2<\frac{1}{1-\delta} \Rightarrow \frac{1}{2}<\delta$. At this level of disclosure, a firm will find it worthwhile to allow publication if:

$$
2 c+\Pi \geq F(1,2 c) \Delta .
$$

Comparing this with (14), it is clear that this condition is more likely to hold as $\delta$ becomes large. Otherwise, if (15) holds, there will be an equilibrium whereby only one firm allows publication while the other does not and there is no scientific research rivalry.

\section{Conclusions}

A far cry from the self-funded gentleman scientist of prior centuries, the production of scientific knowledge is increasingly undertaken in complex organizational settings. A scientist's daily work is structured by funders from a variety of sources, including governments, private firms' internal R\&D allocation, foundations and philanthropists (Gans and Murray 2012). Within this emerging context, the management of scientific work and the nature of the employment relationships between scientists and their funders is of increasing salience to scholars and practitioners. While the particular nature of technical opportunities at the knowledge frontier matter, these deeply organizational and managerial issues are increasingly understood to mediate the productivity of scientists.

It is within an industrial context - where firms employ highly trained research scientists that we have explicitly explored the negotiation over disclosure strategies. Using a theoretical approach to this complex set of choices, we examine scientists' disclosure rights and their 
interaction with the institutional environment facing the firms. By focusing on the tension between scientist preferences for open publication and the concerns of firms that such publication will undermine their ability to appropriate commercial value from their research investments, we were able to analyze disclosure strategies making patenting and publishing decisions meaningfully endogenous and jointly determined. We modeled this tension by considering the negotiations between a single scientist and a single firm over payments, patents, and publication rights. This allowed us to map the primitives of the model (specifically, the value of scientific kudos and the potential assistance disclosures may give to competitors or future licensees) into clear outcomes. Overall this approach moves us far from a setting in which disclosure is regarded as exogenous, shaped only by the type of knowledge and the organizational setting. Moreover, it more clearly maps the daily challenges faced by scientists themselves as well as their managers.

Our principal finding involved an insight into the nature of the intellectual property system and how this drives the interaction between patent and publication disclosure choices that has not been previously identified or highlighted in the literature. While prior work has identified how patenting and publication decisions might be linked for pragmatic and practical reasons (due to prior art rules in the patent system), we showed that these choices interact strategically. Indeed, it is because of the distinctive role of the patent system (in contrast to the system of academic publication) in providing protection over the outcomes of disclosure, that we frequently see patents and publications - patent-paper pairs - as the chosen disclosure regime. This allowed us to not only to contrast the decisions to patent and publish with the decision to keep knowledge secret, but also to examine when choices are made to disclose knowledge in both a patent and a publication.

Our contribution links to a wide range of literature that has examined the organization of scientific work in a range of settings. Most centrally, we provide a bridge between the literature that explores the preferences of individual technical employees on the one hand and the firmlevel approaches to disclosure on the other. With regards to the preferences of individual scientific and technical employees, the literature has continued to puzzle over the complex and multifaceted preferences held by scientists and engineers trained and deeply steeped in the "academy" and yet engaging in knowledge production in an industrial context (see Stern 2004; Sauermann and Cohen 2010). On the other hand, scholars of R\&D management, intellectual 
property management and innovation have examined patent strategy, trade secrecy and the adoption of open science practices at the firm level (Hall and Ham 2001; Ziedonis 2004). By linking the two approaches and recognizing the fact that a firm's disclosure strategies are shaped, in part, by employee preferences for disclosure and vice versa, we resolve a number of the paradoxical and seemingly contradictory results in the literature. From a managerial perspective, our results suggests that firms considering disclosure strategies must not only understand the degree to which these conditions hold, but also must develop approaches that allow for disclosure of all types to be highly coordinated with their critical employees. 


\section{Appendix}

\section{Proof of Proposition 1}

Using Theorem 4 of Milgrom and Shannon (1994), holding $i$ fixed, $d^{*}$, the solution to (1) is nondecreasing in $i$ if the objective function (at the optimal $w$ ) satisfies the single-crossing property in $(d, i)$. Given that total surplus is maximized, the derivative of the objective function with respect to $d_{t}$ is: $b+\delta B-\frac{\partial F\left(i_{t}, d_{t}\right)}{\partial d_{t}}(\Pi-\pi)+i_{t} \delta \frac{1}{3} \frac{\partial k\left(d_{t}\right)}{\partial d_{t}}(1-\gamma)$. A simple comparison on this at $i_{t}=1$ versus $i_{t}=0$ yields the condition of the proposition.

\section{Proof of Proposition 2}

First, consider the conditions for secrecy. If a scientist-firm pair deviated and patented their research, this would result in a change in surplus of $(F(0,0)-F(1,0)) \Delta+\delta \frac{1}{3} K$, so long as the next generation (a) agreed to this license fee and (b) did not themselves choose to patent or publish. Note that, in a secrecy equilibrium, $u_{t}=v_{t}=\frac{1}{2}(\Pi-K-F(0,0) \Delta)$ and $\tau_{t+1}=\frac{1}{3} K$. Substituting this into (5) yields:

$$
\max _{\tau_{t}, w_{t}, d_{t}, i_{t}} \tau_{t}\left(b d_{t}+w_{t}-\frac{1}{2}(\Pi-K-F(0,0) \Delta)\right)\left(\frac{1}{2}(\Pi-K)-F\left(i_{t}, d_{t}\right) \Delta+\frac{1}{2} F(0,0) \Delta+i_{t} \delta \frac{1}{3} K-w_{t}-\tau_{t}\right) .
$$

As $\tau_{t}$ and $w_{t}$ are positive, the choice of $i_{t}$ and $d_{t}$ is determined by total surplus. Under the conditions for secrecy, increasing either of these reduces total surplus and hence, even if a licensing agreement is signed upon deviation, these choices will not change. Similarly, deviating to publication will reduce total surplus as it assists entry, does not result in kudos (as there is no future publication) and reduces future research capital costs (something not captured by the current generation). Finally, deviating to both patents and publications increases $u_{t}$ and $v_{t}$ but does not otherwise change the drivers of licensing. Hence, it results in a lower return than a move to commercial science alone and is not profitable.

Second, consider the conditions for commercial science. A deviation to secrecy will not change the incentives for the next generation to engage in commercial science (although it will change their costs), and so the condition supporting commercial science is the mirror image of the condition supporting secrecy. A deviation to patent-paper pairs would reduce commercial returns - both immediately and in the future - and not offer the benefit of additional scientific kudos as it would still maximize total surplus of future pairs not to publish. This is also true for a move to open science. Hence, the existence of an equilibrium with commercial science is solely driven by whether $F(1,0) \leq F(0,0)$ and $\frac{b}{\Delta}<\frac{\partial F(0,0)}{\partial d}$.

Third, open science results in disclosure equal to $d^{*}(0)$ with scientists and firms earning an expected payoff of $\frac{1}{2}\left((b+\delta B) d^{*}(0)+\Pi-F\left(0, d^{*}(0)\right) \Delta\right)$. Secrecy would reduce total surplus if $\frac{b+\delta B}{\Delta}>\frac{\partial F(0,0)}{\partial d_{t}}$. In contrast, obtaining a patent increases total surplus by $\frac{\delta \frac{1}{3}\left(K-k\left(d_{t}^{*}(1)\right)(1-\gamma)\right)}{\Delta}-\left(F\left(1, d_{t}^{*}(1)\right)-F\left(0, d_{t}^{*}(0)\right)\right)$, which is negative by the condition of the proposition.

Finally, by reverting to commercial science, total surplus falls by $\frac{b+\delta B}{\Delta}-\frac{F\left(0, d_{t}^{*}(0)\right)-F(1,0)}{d_{t}^{*}(0)}-\frac{\delta \frac{1}{3} K}{\Delta d_{t}^{*}(0)}$. 
Finally, patent-paper pairs result in a level of disclosure equal to $d^{*}(1)$. This will be preferred to open science if $\frac{\delta_{3}^{\frac{1}{3}}\left(K-k\left(d_{t}^{*}(1)(1-\gamma)\right)\right.}{\Delta} \geq F\left(1, d_{t}^{*}(1)\right)-F\left(0, d_{t}^{*}(0)\right)$ and to commercial science if $\frac{b+\delta B}{\Delta}>\frac{\partial F(1,0)}{\partial d_{t}}-\frac{\partial k(0)}{\partial d_{t}} \frac{\delta \frac{1}{3}(1-\gamma)}{\Delta}$. Compared to secrecy, patent-paper pairs result in higher total surplus if: $(b+\delta B) d^{*}(1)+\delta \frac{1}{3}\left(K-k\left(d_{t}^{*}(1)\right)(1-\gamma)\right)>\left(F\left(1, d^{*}(1)\right)-F(0,0)\right) \Delta$. Note, however, that if the other two conditions hold, then this holds as well, and so is redundant.

\section{Remark on the zero wage case}

Proposition 1 holds qualitatively and, in some cases, are strengthened when (A1) does not hold and, specifically, wages may be zero in equilibrium. First, Proposition 1 demonstrates that, under (A1), $\frac{\partial F(1, d)}{\partial d} \leq \frac{\partial F(0, d)}{\partial d}$ is a necessary condition for disclosure to (weakly) increase if a patent is taken out. The following proposition demonstrates that, when wages are zero, the disclosure can increase with patent protection even if $\frac{\partial F(1, d)}{\partial d} \leq \frac{\partial F(0, d)}{\partial d}$ does not hold.

Proposition A1. Let $\hat{d}(i)=\arg \max _{d} b d-F(i, d)(\Pi-\pi)$. If $\hat{d}(1)<\underline{d}$, then $\frac{\partial F(1, d)}{\partial d} \leq \frac{\partial F(0, d)}{\partial d}$ is a necessary condition for $d^{*}(1) \geq d^{*}(0)$. If $\hat{d}(1)>\underline{d}$, then it is possible that $d^{*}(1) \geq d^{*}(0)$ when $\frac{\partial F(1, d)}{\partial d}>\frac{\partial F(0, d)}{\partial d}$.

Proof: Note that when $d^{*}=0$ (which occurs if $\frac{b}{\Pi-\pi} \leq \frac{\partial F(i, 0)}{\partial d}$ ), in equilibrium, $w>0$, as this is the only way to ensure the scientist's participation. In this case, the Nash objective functions are:

- Secrecy: $\frac{1}{4}\left(\Pi-k-(F(0,0)(\Pi-\pi)-\underline{u})^{2}\right.$.

- Commercial Science: $\frac{1}{4}(\Pi-k-F(1,0)(\Pi-\pi)-\underline{u})^{2}$.

There are two cases to consider of relevance: (i) that $\hat{d}(0)<\underline{d}$ and (ii) that $\hat{d}(0)>\underline{d}$. In the former, the objective function for open science is:

- Open Science: $\frac{1}{4}(\Pi-k-F(0, \hat{d}(1))(\Pi-\pi)-\underline{u})^{2}$.

While in the latter it is:

- Open Science: $\left(\Pi-k-F\left(0, d^{*}(0)(\Pi-\pi)\right)\left(b d^{*}(0)-\underline{u}\right)\right.$.

The maximized objective function for patent-paper pairs is:

- Patent-Paper Pairs: $\left(\Pi-k-F\left(1, d^{*}(1)(\Pi-\pi)\right)\left(b d^{*}(1)-\underline{u}\right)\right.$.

For the case where $\hat{d}(0)<\underline{d}$, the equilibrium outcomes are:

- Secrecy $\quad(i=d=0) \quad$ if $\quad \frac{b}{\Pi-\pi} \leq \frac{\partial F(0,0)}{\partial d}, \quad F(1,0)<F(0,0) \quad$ and

$$
\frac{1}{4}\left(\Pi-k-(F(0,0)(\Pi-\pi)-\underline{u})^{2}>\left(\Pi-k-F\left(1, d^{*}(1)(\Pi-\pi)\right)\left(b d^{*}(1)-\underline{u}\right) .\right.\right.
$$

- Commercial Science $(i=1, d=0)$ if $\frac{b}{\Pi-\pi} \leq \frac{\partial F(1,0)}{\partial d}$ and $F(1,0) \geq F(0,0)$.

- Open Science $(i=0, \quad d>0)$ if $\quad \frac{b}{\Pi-\pi}>\frac{\partial F(0,0)}{\partial d} \quad$ and $\frac{1}{4}\left(b d^{*}(0)+\Pi-k-\left(F\left(0, d^{*}(0)\right)(\Pi-\pi)-\underline{u}\right)^{2}>\left(\Pi-k-F\left(1, d^{*}(1)(\Pi-\pi)\right)\left(b d^{*}(1)-\underline{u}\right)\right.\right.$.

$$
\begin{aligned}
& \text { - Patent-Paper Pairs } \quad(i=1, \quad d>0) \quad \text { if } \quad \frac{b}{\Pi-\pi} \geq \frac{\partial F(1,0)}{\partial d}, \\
& \frac{1}{4}\left(b d^{*}(0)+\Pi-k-\left(F\left(0, d^{*}(0)\right)(\Pi-\pi)-\underline{u}\right)^{2} \leq\left(\Pi-k-F\left(1, d^{*}(1)(\Pi-\pi)\right)\left(b d^{*}(1)-\underline{u}\right)\right.\right. \\
& \text { and } \frac{1}{4}\left(\Pi-k-(F(0,0)(\Pi-\pi)-\underline{u})^{2} \leq\left(\Pi-k-F\left(1, d^{*}(1)(\Pi-\pi)\right)\left(b d^{*}(1)-\underline{u}\right) .\right.\right.
\end{aligned}
$$


For the case where $\hat{d}(0) \geq \underline{d}$, the equilibrium outcomes are:

- Secrecy $(i=d=0) \quad$ if $\quad \frac{b}{\Pi-\pi} \leq \frac{\partial F(0,0)}{\partial d}, \quad F(1,0)<F(0,0) \quad$ and

$$
\frac{1}{4}\left(\Pi-k-(F(0,0)(\Pi-\pi)-\underline{u})^{2}>\left(\Pi-k-F\left(1, d^{*}(1)(\Pi-\pi)\right)\left(b d^{*}(1)-\underline{u}\right) .\right.\right.
$$

- Commercial Science $(i=1, d=0)$ if $\frac{b}{\Pi-\pi} \leq \frac{\partial F(1,0)}{\partial d}$ and $F(1,0) \geq F(0,0)$.

$$
\begin{aligned}
& \text { - Open Science }(i=0, \quad d>0) \text { if } \frac{b}{\Pi-\pi}>\frac{\partial F(0,0)}{\partial d} \quad \text { and } \\
& \frac{1}{4}\left(b d^{*}(0)+\Pi-k-\left(F\left(0, d^{*}(0)\right)(\Pi-\pi)-\underline{u}\right)^{2}>\left(\Pi-k-F\left(1, d^{*}(1)(\Pi-\pi)\right)\left(b d^{*}(1)-\underline{u}\right) .\right.\right. \\
& \text { - Patent-Paper Pairs } \quad(i=1, \quad d>0) \quad \text { if } \quad \frac{b}{\Pi-\pi} \geq \frac{\partial F(1,0)}{\partial d} \text {, } \\
& \frac{1}{4}\left(b d^{*}(0)+\Pi-k-\left(F\left(0, d^{*}(0)\right)(\Pi-\pi)-\underline{u}\right)^{2} \leq\left(\Pi-k-F\left(1, d^{*}(1)(\Pi-\pi)\right)\left(b d^{*}(1)-\underline{u}\right)\right.\right. \\
& \text { and }\left(\Pi-k-F\left(0, d^{*}(0)(\Pi-\pi)\right)\left(b d^{*}(0)-\underline{u}\right) \leq\left(\Pi-k-F\left(1, d^{*}(1)(\Pi-\pi)\right)\left(b d^{*}(1)-\underline{u}\right)\right. \text {. }\right.
\end{aligned}
$$

Finally, note that the derivative of the Nash objective function (with $w=0$ ) with respect to $d$ can be rewritten as $\Pi-k-F(i, d)(\Pi-\pi)-\left(d-\frac{u}{b}\right) \frac{\partial F(i, d)}{\partial d}(\Pi-\pi)$. As $b$ increases, this marginal condition falls indicating that, when $w=0, d^{*}(i)$ is non-increasing in $b$.

This proposition highlights an additional complementarity between patents (and commercial returns in general) and publication that is less obvious but is derived from the formal model. When $\hat{d}(1)>\underline{d}$, when a patent is taken out, the negotiated level of disclosure will be high enough that, in equilibrium, $w^{*}=0 .{ }^{34}$ In this case, if a patent is granted, stronger patents increase commercial returns (as $F(1, d)<F(0, d)$ ). As noted earlier, since wages are zero when there is a publication, the only way this additional surplus can be transferred to the scientist is by allowing more disclosure. Similarly, any policy changes that strengthen patent protection and make patents more likely to be undertaken will make disclosure more likely. Thus, in contrast to concerns that changes (such as the Bayh-Dole Act) would diminish levels of openness and publications, there are stronger incentives to generate published disclosures for commercially funded projects as patent protection becomes stronger and more commercially desirable.

\footnotetext{
${ }^{34}$ While the proposition endogenously derives when wages are constrained at zero, in some environments, such payments may be prohibited. In such cases, the source of complementarity highlighted here will always be present.
} 
Figure 2a: Complementarity

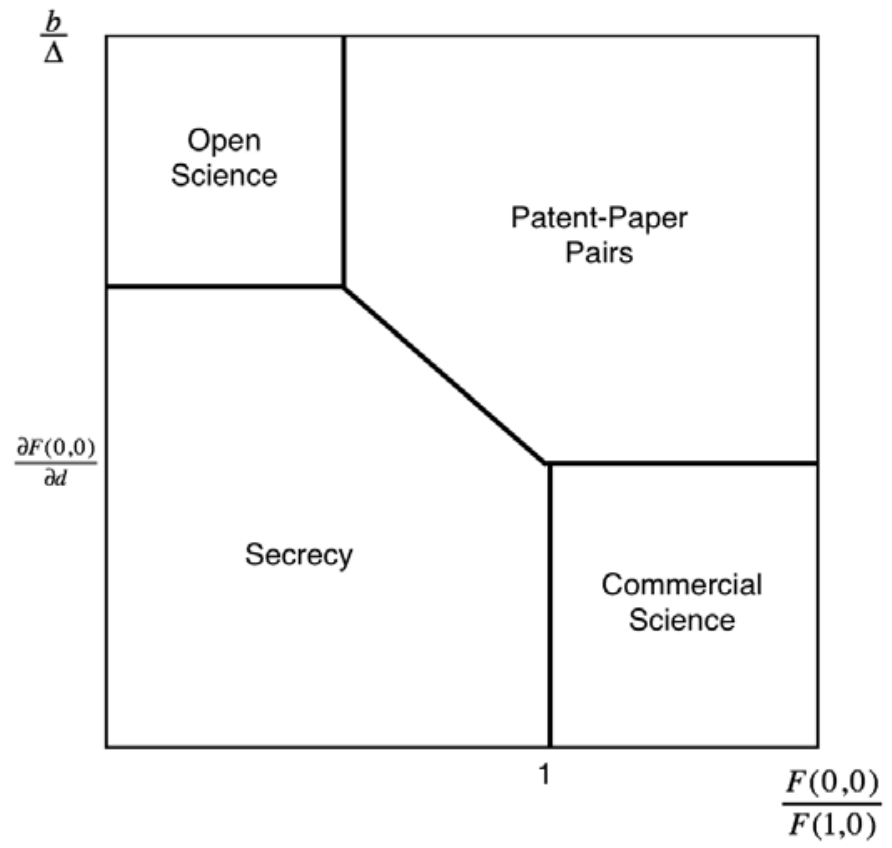

Figure 2b: Substitutability

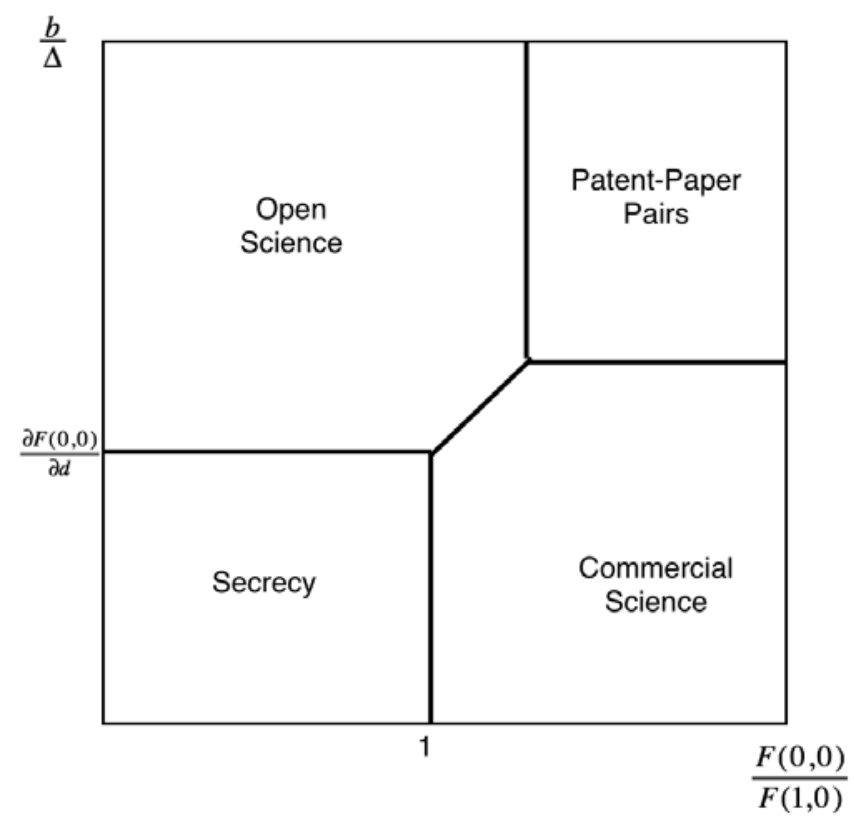




\section{References}

Aghion P, Dewatripont M, Stein J (2009) Academic freedom, private-sector focus and the process of innovation. RAND J. Econ. 39(3):617-635.

Arrow K (1962) Economic welfare and the allocation of resources for invention. Nelson R, ed. The Rate and Direction of Inventive Activity (Princeton University Press, Princeton, NJ), 609-625.

Azoulay P, Ding W, Stuart T (2009) The impact of academic patenting on the rate, quality and direction of (public) research output. J. Ind. Econ. 75:637-676.

Baker S, Mezzetti C (2005) Disclosure as a strategy in a patent race. J. Law Econ. 48(2):173-194.

Bar T (2006) Defensive publications in an R\&D Race. J. Econ. Manage. Strat. 15(1):229-254.

Bar-Gill O, Parchomovsky G (2003) The value of giving away secrets. Va. L. Rev. 89:1857-1895.

Bhaskarabhatla A, Hedge D (2014) An organizational perspective on patenting and open innovation. Organ. Sci. Forthcoming.

Bok D (2003) Universities in the Marketplace: The Commercialization of Higher Education (Princeton University Press, Princeton, NJ).

Cockburn I, Henderson R (1998) Public-private interaction and the productivity of pharmaceutical research, J. Indust. Econ. 46 (2).

Cohen S, Chang A, Boyer J, Helling R (1973) Construction of biologically functional bacterial plasmids in vitro. Proc. Natl. Acad. Sci. 70:3240-3244.

Cohen W, Levinthal D (1990) Absorptive capacity: a new perspective on learning and innovation, Admin. Sci. Quarterly. 35 (1): 128-152.

Dasgupta P, David PA (1994) Towards a new economics of science. Res. Policy 23:487-521.

David, PA (2008) The historical origins of "open science": An essay on patronage, reputation and common agency contracting in the scientific revolution. CAS. 3(2):Article 5.

Denicolo V, Franzoni LA (2004) Patents, secrets, and the first-inventor defense. J. Econ. Manage. Strat. 13(3):517-538.

Ducor P (2000) Intellectual property: Coauthorship and coinventorship. Science 289:873-875.

Erkal N (2005) The decision to patent, cumulative innovation, and optimal policy. Int. J. Ind. Organ. 23(7-8):535-562.

Fehder DC, Murray F, Stern S (2013) Intellectual property rights and the evolution of scientific journals as a platform. mimeo., MIT.

Fabrizio K, Di Minin A (2008) Commercializing the laboratory: The relationship between faculty patenting and publishing. Res. Policy 37:914-931

Fu C, Turck CW, Kurosaki T, Chan AC (1998) BLNK: A central linker protein in B cell activation. Immunity 9(1):93-103.

Gans, JS, Murray FE (2012) Funding scientific knowledge: Selection, disclosure and the public-private portfolio. Lerner J, Stern, S, eds. Rate and Direction of Inventive Activity (National Bureau of Economic Research, Cambridge, MA), Chapter 1.

Garfield E (1973) Citation frequency as a measure of research activity and performance. Essays of an Information Scientist. 1:406-408.

Geison G L (1995) The Private Science of Louis Pasteur (Princeton University Press, Princeton, NJ).

Gilbert RJ, Newbery DMG (1982) Preemptive patenting and the persistence of monopoly. Amer. Econ. Rev. 72 (3): 514-526.

Gittleman M, Kogut B (2003) Does good science lead to valuable knowledge? Biotechnology firms and the evolutionary logic of citation patterns. Manage. Sci. 49(4):366-382. 
Haeussler C, Jiang L, Thursby J, Thursby M (2011) Sharing among competing researchers. Mimeo., Georgia Tech.

Hall BH, Ham Ziedonis R (2001) The patent paradox revisited: An empirical study of patenting in the U.S. semiconductor industry, 1979-1995. RAND J. Econ. 32:1:101-128.

Heller M, Eisenberg R (1998). Can patents deter innovation? The anticommons in biomedical research. Science 280(5364):698-701.

Hellmann T (2007) The role of patents for bridging the science to market gap. J Econ. Behav Organ. 63(4):624-647.

Henderson R, Cockburn I (1996) Scale, scope and spillovers: The determinants of research productivity in drug discovery. RAND J. Econ. 27(1):32-59.

Huang K, Murray F (2009) Does patent strategy shape the long-run supply of public knowledge? Evidence from the human genome. Acad Manage J. 52(6):1193-1221.

Jensen R, Thursby J, Thursby, MC (2010) University-industry spillovers, government funding, and industrial consulting. Working paper, No. 15732, National Bureau of Economic Research.

Jeon D-S, Menicucci D (2008) Money, fame and allocation of talent: Brain drain and the institution of science. J Econ. Behav Organ. 66(3-4):558-581.

Johnson J (2005) Defensive publication by a leading firm. Mimeo., Cornell University.

Katz M, Shapiro C (1987) R\&D rivalry with licensing or imitation. Amer. Econ Rev. 77 (3): 402-420.

Lacetera N (2009) Different missions and commitment power in R\&D organization: Theory and evidence on industry-university relations. Organ. Sci. 20(3):565-582.

Lampe R (2012) Strategic citations. Rev. Econ. Stat. 94(1):320-333.

Lemley MA, Shapiro C (2005) Probabilistic patents. J. Econ. Perspect. 19(2):75-98.

Lerner J (1994) The importance of trade secrecy: Evidence from civil litigation. Mimeo., Harvard University.

Lerner J, Tirole J (2005) The economics of technology sharing: Open source and beyond. J. Econ. Perspect. 19(2):99-120.

Levin R, Klevorick A, Nelson R, Winter S (1987) Appropriating the returns from industrial research and development. Brookings Pap. Eco. Ac. 3:783-831.

Lim K (1999) Do firms have to perform basic research in order to capture spillovers. Mimeo., MIT Sloan School.

Lim K (2004) The relationship between research and innovation in the semiconductor and pharmaceutical industries (1981-1997). Res. Policy 33(2):287-321.

Lowry S (1988) Inevitable disclosure trade secret disputes: Dissolutions of concurrent property interests. Stanford Law Rev. 40(2):519-544.

Macho-Stadler I, Pérez-Castrillo D, Veugelers R (2007) Licensing of university inventions: The role of a technology transfer office. Int. J. Ind. Organ. 25(3):483-510.

Machlup F, Penrose E (1950) The patent controversy in the nineteenth century. J. Econ. Hist. 10(1):1-29.

Marx M, Strumsky D, Fleming L (2009) Mobility, skills, and the Michigan non-compete experiment. Manage. Sci. 55(6):875-889.

Merton RK (1957) Priorities in scientific discovery: A chapter in the sociology of science. American Sociol. Rev. 22(6):635-659.

Merton RK (1973) The normative structure of science. The Sociology of Science: Theoretical and Empirical Investigations (University of Chicago Press, Chicago, IL), 267-280.

Milgrom, P.R. \& C. Shannon. 1994. "Monotone Comparative Statics," Econometrica, 62, 157-80.

Mokyr J (2004) The Gifts of Athena. (Princeton University Press: Princeton, NJ). 
Moser P (2005) How do patent laws influence innovation? Evidence from nineteenth-century world fairs. Am. Econ. Rev. 95(4):1215-1236.

Mowery D, Nelson RR, Sampat B, Ziedonis A (2004) Ivory Tower and Industrial Innovation: UniversityIndustry Technology Transfer (Stanford University Press, Palo Alto, CA).

Mukherjee A, Stern S (2009) Disclosure or secrecy: The dynamics of open science. Int. J. Ind. Organ. 27(3):449-462.

Murray F (2002) Innovation as co-evolution of scientific and technological networks: Exploring tissue engineering. Res. Policy 31(8-9):1389-1403.

Murray F (2010) The oncomouse that roared: Hybrid exchange strategies as a source of productive tension at the boundary of overlapping institutions. Am. J. Sociol. 116(2):341-388.

Murray F, Stern S (2007) Do formal intellectual property rights hinder the free flow of scientific knowledge? An empirical test of the anti-commons hypothesis. J. Econ. Behav. Organ. 63(4):648-687.

Nelson RR (2004) The market economy and the scientific commons. Res. Policy 33(3):455-471.

Neuman W (2010) A man with muffin secrets, but no job with them. New York Times, 7 August. Accessed $7^{\text {th }}$ August 2010, http://www.nytimes.com/2010/08/07/business/07muffin.html.

O’Mahony L, Dahlander S (2011) Progressing to the center: Coordinating project work. Org Sci. 22 (4): 961-979.

Rabinow P (1996) Making PCR: A Story of Biotechnology (University of Chicago Press, Chicago, IL).

Radcliffe W (1947) The Secret Instrument: The Birth of the Midwifery Forceps (William Heinemann. Medical Books, New York).

Reinganum J (1989) The timing of innovation: Research, development and diffusion. R. Schmalensee \& R. Willig (eds.), Handbook of Industrial Organization, Vol. 1, (North-Holland, Amsterdam), Chpt 14.

Roach M, Sauermann H (2010) A taste for science? PhD scientists' academic orientation and selfselection into research careers in industry. Res. Policy 39(3):422-434.

Romer PM (1990) Endogenous technological change. J. Polit. Econ. 98(5, pt. 2):S71-S102.

Rosenberg N (1990) Why do firms do basic research (with their own money)? Res. Policy 19(2):165-174.

Sauermann H, Roach M (2014) Not all scientists pay to be scientists: PhDs' preferences for publishing in industry employment. Res. Policy 43(1):32-47.

Sauermann H, Stephan PE (2010) Twins or strangers? Differences and similarities between industrial and academic science. Working paper, No. 16113, National Bureau of Economic Research.

Sauermann H, Cohen W (2010) What makes them tick? Employee motives and firm innovation. Manage. Sci. 65(12):2134-2153.

Scotchmer S, Green J (1990) Novelty and disclosure in patent law. RAND J. Econ. 21(1):131-140.

Shockley W (1949) The theory of p-n junctions in semiconductors and p-n junction transistors. Bell Syst. Tech. J. 28:435-489.

Stephan P (2011) How Economics Shapes Science (Harvard University Press, Cambridge, MA).

Stern S (2004) Do scientists pay to be scientists? Manage. Sci. 50(6):835-853.

Stokes D (1997) Pasteur's Quadrant: Basic Science and Technological Innovation (The Brookings Institution, Washington, DC).

Williams H (2010) Intellectual property rights and innovation: Evidence from the human genome. Mimeo., Harvard University.

Wuchty S, Jones BF, Uzzi B(2007) The increasing dominance of teams in production of knowledge. Science. 316 (5827): 1036-1039. 
Ziedonis R (2004) Don't fence me in: Fragmented markets for technology and the patent acquisition strategies of firms. Manage. Sci. 50(6):804-820. 